\title{
Experimental study on the flow and heat transfer characteristics of nanofluids in double-tube heat exchangers based on thermal efficiency assessment
}

Cong Qi ${ }^{\text {a, b, c, * }}$, Tao Luo ${ }^{\text {a, b }}$, Maoni Liu ${ }^{\text {a, b }}$, Fan Fan ${ }^{\text {a, b}}$, Yuying Yan ${ }^{\text {c }}$

a Jiangsu Province Engineering Laboratory of High Efficient Energy Storage Technology and Equipments, China University of Mining and Technology, Xuzhou 221116, China

${ }^{\mathrm{b}}$ School of Electrical and Power Engineering, China University of Mining and Technology, Xuzhou 221116, China

${ }^{c}$ Fluids \& Thermal Engineering Research Group, Faculty of Engineering, University of Nottingham, Nottingham NG7 2RD, UK

Abstract: Thermal performance and pressure drop of $\mathrm{TiO}_{2}-\mathrm{H}_{2} \mathrm{O}$ nanofluids in double-tube heat exchangers are investigated. The influence of the thermal fluid (water) volume flow rates $\left(q_{v}=1-5 \mathrm{~L} / \mathrm{min}\right)$, nanoparticle mass frictions $(\omega=0.0 \%, 0.1 \%$, $0.3 \%$ and $0.5 \%$ ), nanofluids locations (shell-side and tube-side), Reynolds numbers of nanofluids ( $R e=3000-12000)$, and the structures of inner tubes (smooth tube and corrugated tube $)$ is analyzed. Results indicate that nanofluids $(\omega=0.1 \%, 0.3 \%$ and $0.5 \%$ ) can improve the heat transfer rate by $10.8 \%, 13.4 \%$ and $14.8 \%$ at best compared with deionized water respectively, and the number of transfer units (NTU) and effectiveness are all improved. The pressure drop can be increased by $51.9 \%$ (tube-side) and $40.7 \%$ (shell-side) at best under the condition of using both nanofluids and corrugated inner tube. When the nanofluids flow in the shell-side of the corrugated double-tube heat exchanger, the comprehensive performance of nanofluids-side is better than that of the smooth double-tube heat exchanger.

Key words: Nanofluids; Double-tube heat exchanger; Thermal efficiency; Heat transfer enhancement

*Correspondence author.

E-mail: qicong@cumt.edu.cn (C. Qi); luotao@cumt.edu.cn (T. Luo); liumaoni@cumt.edu.cn (M. Liu); fanfan@cumt.edu.cn (F. Fan); yuying.yan@nottingham.ac.uk (Y. Yan) 


$\begin{array}{lll}27 & A & \text { heat transfer surface area, } \mathrm{m}^{2} \\ 28 & c_{\mathrm{p}} & \text { specific heat, } \mathrm{J} \cdot \mathrm{kg}^{-1} \cdot \mathrm{K}^{-1} \\ 29 & d & \text { equivalent diameter, } \mathrm{m} \\ 30 & f & \text { the frictional resistance coefficient } \\ 31 & h & \text { the overall heat transfer coefficient, } \mathrm{W} / \mathrm{m}^{2} \mathrm{~K} \\ 32 & L & \text { length of tube, } \mathrm{m} \\ 33 & m & \text { the mass flow rate of the hot water, } \mathrm{kg} / \mathrm{s} \\ 34 & N T U & \text { number of transfer units } \\ 35 & P & \text { pressure, } \mathrm{Pa} \\ 36 & \Delta P & \text { pressure drop, Pa } \\ 37 & q v & \text { the volume flow rate of the hot water, } \mathrm{L} / \mathrm{min} \\ 38 & Q & \text { the heat transfer rate, } \mathrm{W} \\ 39 & R e & \text { Reynolds number } \\ 40 & T & \text { the fluid temperature, } \mathrm{K} \\ 41 & \Delta T_{\mathrm{m}} & \text { the logarithmic mean temperature difference, } \mathrm{K} \\ 42 & u & \text { velocity, } \mathrm{m} / \mathrm{s} \\ 43 & \text { Greek } & \text { symbols } \\ 44 & \delta & \text { wall thickness of tube, } \mathrm{m} \\ 45 & \varepsilon & \text { effectiveness } \\ 46 & \rho & \text { density, } \mathrm{kg} / \mathrm{m}^{3} \\ 47 & \omega & \text { mass fraction } \\ 48 & \text { Subscripts } \\ 49 & \text { ave } & \text { average } \\ 50 & \text { in } & \text { inlet } \\ 51 & \text { min } & \text { minimum } \\ 52 & \text { max } & \text { maximum } \\ 53 & \mathrm{nf} & \text { nanofluids } \\ 54 & \text { out } & \text { outport } \\ 55 & \mathrm{~W} & \text { thermal water } \\ & & \end{array}$




\section{Introduction}

Nanofluids, as heat transfer medium, have been applied into various fields because of their excellent thermal performance. Many investigators not only measured the thermal conductivity $[1,2,3]$, but also developed some empirical formulas of thermal conductivity $[4,5,6,7]$, a more detailed review of the research on the preparation methods and thermal property parameters of nanofluids can be found in the literature [8]. Furthermore, for the practical application of nanofluids, a guideline for the selection of nanofluids has also been studied [9]. The application fields of nanofluids mainly including full-spectrum photo-thermal conversion [10, 11], tunable and recyclable photovoltaic/thermal applications $[12,13]$, vapor generation by different nanoparticles or nanofluids $\left(\mathrm{Fe}_{3} \mathrm{O}_{4} @ \mathrm{CNT}\right.$ nanoparticles [14], carbon-nanotube nanofluids [15], graphene oxide nanofluids [16] and MCE/HP/Au mixed nanoparticles [17]), boiling heat transfer [18], thermal energy storage [19, 20], CPU cooling [21, 22, 23, 24], microchannel [25, 26], heat pipe [27, 28], and so on.

In the field of heat exchange equipment, there are two crucial heat transfer methods: free convection and forced convection. For free convection, lots of researches have been reported by published literatures. Shi et al. [29] performed an investigation on the free convection of $\mathrm{Fe}_{3} \mathrm{O}_{4} @ \mathrm{CNT}$ nanofluids in a rectangular cavity under magnetic field conditions using experimental and numerical simulation methods. Results indicated that the direction of magnetic field can regulate the thermal performance of nanofluids. Selimefendigil et al. reported on a numerical method which was used to study the free convection of CNT-water nanofluids in a 
two-dimension enclosure with corrugated partition [30] and three kinds of nanofluids in a three dimensional cavity with rotating circular cylinders [31] respectively. It was discovered that the thermal performance of nanofluids decreases with the height of the triangular waves in the two-dimension enclosure, and the rotational direction of circular cylinders also has a significant role in heat transfer. Sajjadi et al. [32] represented a numerical simulation study on the free convection of MWCNT- $\mathrm{Fe}_{3} \mathrm{O}_{4} /$ water nanofluids in a square cavity full of porous media. Results showed that the increasing Darcy number and porosity can enhance the thermal performance. The natural convection of nanofluids in various cavities is widely researched. For example, nanofluids in an inclined cavity [33], an open cavity [34], an open inclined cavity [35], a cavity with a heat-generating element [36], a tilted porous cavity [37], a baffled U-shaped enclosure [38], a three dimensional porous cavity [39], a annular cavity filled with porous media under electric field [40], a semi annulus [41], and a square cavity full of a porous foam [42]. The influence of Rayleigh number, nanoparticle concentration, porous layer, cavity inclination angle, heat source location, and cavity aspect ratio on the thermal performance was analyzed. Results presented that nanofluids have more excellent heat transfer compared with base fluid.

Also, many studies have been conducted on the forced convection. Xu et al. [43] reported on a numerical simulation method which was obtained to study the flow and thermal performances of $\mathrm{Al}_{2} \mathrm{O}_{3}-\mathrm{H}_{2} \mathrm{O}$ nanofluids flowing through a channel filled with $\mathrm{Cu}$ metal-foam. It was obtained that thermal performance of nanofluids in metal foam is effectively improved at the expense of a large increase in pressure drop. Mohebbi et 
100

101

102

103

104

105

106

107

108

109

110

111

112

al. [44] adopted a lattice Boltzmann method to research the forced convection of three kinds of nanofluids $\left(\mathrm{CuO}, \mathrm{Al}_{2} \mathrm{O}_{3}\right.$ and $\left.\mathrm{TiO}_{2}\right)$ flowing through a channel with blocks at the top and bottom of wall. Conclusions indicated that as the space between the blocks decreases, the thermal performance increases. Karimi et al. [45] applied MgO-MWCNTs/EG nanofluids into heat exchanger, and results indicated that nanofluids with concentration $1 \%$ can improve the thermal performance by $20 \%$, but the pressure drop also increases. Tirandaz et al. [46] performed a numerical investigation to research the forced convection in a helical annulus filled with a porous medium. And two different boundary conditions is considered. Conclusions indicated that the Nusselt number is insensitive to the second-order torsion of the dimensionless curvature, and the enhancement of the Nusselt number is more pronounced at higher curvature values. Mehrali et al. [47] performed an experimental study on the thermal performance and flow characteristic of grapheme nanoplatelet nanofluids in a stainless steel tube, and obtained that the thermal performance of nanofluids can be improved by $83-200 \%$ compared with base fluid. In addition to the analysis of quantity of energy, Mehrali et al. [48, 49] also investigated the entropy generation of nanofluids under forced flow from the quality. Moradikazerouni et al. [50] carried out a numerical method to investigate the convection performance of $\gamma$-AlOOH nanofluids in a wavy channel, and explore the influence of the Reynolds number, amplitude of wavy channel and nanoadditive fraction. Mirzaei et al. [51] investigated the thermal performance of $\mathrm{Al}_{2} \mathrm{O}_{3}-\mathrm{H}_{2} \mathrm{O}$ nanofluids under laminar flow in micro channel and obtained that the influence of the variable is obviously, and the 
122 influence of temperature variation on thermal performance cannot be neglected. Sun 123 et al. researched the thermal performance of nanofluids in an external thread tubes 124 which own a built-in twisted belt [52], plate heat exchanger [53], and copper tubes [54] 125 respectively. Results proved that Reynolds number and nanoparticle concentration are 126 all positive factors for the thermal performance improvement. Sheikholeslami et al. 127 carried out a study on the heat exchanger enhancement and flow characteristics of 128 nanofluids in a double-tube heat exchanger [55], a porous semi annulus [56], a porous 129 lid driven cubic cavity [57], a three dimension square cavity [58], and an annular 130 cavity [59, 60], explored the influence of nanoparticle fraction and magnetic field on 131 thermal exchange, and found that these factors can effectively improve the thermal 132 performance. Ranjbarzadeh et al. [61] carried out an empirical analysis method to 133 investigate the thermal performance and flow characteristic of nanofluids in an 134 isothermal pipe under forced convection condition. Results showed that nanofluids 135 can improve the thermal performance by $40.3 \%$ compared with base fluid. 136 Moradikazerouni et al. [62] studied the influence of the entrance channel shapes on 137 the heat transfer enhancement in a micro-channel heat sink using a numerical method, 138 and results showed that the triangular shape provides the best thermal performance in 139 the five channel configurations. Dehghan et al. [63] represented an investigation on 140 the thermal performance in microchannels enhanced by porous materials and obtained 141 that the comprehensive evaluation of heat transfer and pressure drop can be 142 effectively enhanced by inserting a thin porous insert. Dehghan et al. [64] also 143 investigated the influence of $\mathrm{Al}_{2} \mathrm{O}_{3}$-water nanofluids on the forced convection in a 
microchannel heat sink using a numerical simulation. Nojoomizadeh et al. [65] carried out an numerical method to explore the effects of permeability on the forced convection of nanofluids in a micro channel, the investigation indicated that the thermal performance increases with the decreasing permeability. Moradikazerouni et al. [66] reported a numerical simulation method which was used to study the influence of laminar forced convection on the heat transfer enhancement in a CPU heat sink, compared with convection-radiation, the pure convection has less thermal performance improvement. Ranjbarzadeh et al. [67] represented an experimental investigation on the forced convection of nanofluids in a copper tube and obtained that Nusselt number can be increased by $51.4 \%$ compared with water. Biglarian et al. [68] reported on a study to explore the forced convection of various nanofluids $(\mathrm{Cu}$, $\mathrm{Ag}, \mathrm{Al}_{2} \mathrm{O}_{3}, \mathrm{TiO}_{2}$ ) and obtained that $\mathrm{Cu}$ nanofluids show the largest enhancement ratio. Many enhanced tubes and nanofluids are applied to enhance the thermal performance. Naphon et al. reported an investigation on the thermal performance and pressure drop of nanofluids in a helically corrugated tube [69], a micro-fins tube [70], a spirally coiled tube [71], and a micro-channel heat sink [72]. Qi et al. also did lots of work in enhanced tubes, for example, spiral tubes [73], corrugated tubes [74, 75, 76], triangular tubes [77, 78], a circular tube with rotating twisted [79], a horizontal elliptical tube [80]. From above references, it was found that nanofluids can all improve the thermal performance at the expense of a significant increase in pressure drop. Therefore, scholars have also done some work on the comprehensive assessment of the heat transfer enhancement and flow resistance [81, 82, 83]. 

thermal performance of nanofluids in a single enhanced tube. However, there are few published literatures on the application of nanofluids and enhanced tube into double-tube heat exchanger. The research proposal of this paper is to study the thermal performance and pressure drop of $\mathrm{TiO}_{2}-\mathrm{H}_{2} \mathrm{O}$ nanofluids in the corrugated double-tube heat exchanger using experimental method, and the innovations are as

172 follows: Corrugated tube is applied in the tube-side instead of smooth tube; Effects of 173 nanofluids location, nanoparticle mass fraction and thermal fluid flow rate on the 174 thermo-hydraulic performances of nanofluids in the double-tube heat exchanger are 175 investigated based on thermal efficiency assessment; The effectiveness and the NTU 176 of double-tube heat exchanger are analyzed.

\section{Experimental Method}

\subsection{Nanofluids preparation and stability}


obtained.

Although nanofluids have better heat transfer enhancement effects, the stability and economics of nanofluids are currently the main problems and shortcomings. Hence, the details on the stability and thermophysical parameters of $\mathrm{TiO}_{2}-\mathrm{H}_{2} \mathrm{O}$ nanofluids have been investigated in previous published reference [80]. The prepared nanofluids have good stability after standing for 20 days.

\subsection{Experimental system}

The schematic diagram and the real experimental setup of the corrugated double-tube heat exchanger experimental setup are shown in Fig. 1 and Fig. 2 respectively. The experimental setup consists of a test section, a low-temperature thermostat bath, a hot water tank, two pumps, two valves, two flow meters and collection tanks. The inner tube (corrugated tube) in test section is made of stainless steel with $D_{\max }=15.8 \mathrm{~mm}$ and $D_{\min }=11.2 \mathrm{~mm}$, the wall thickness is $\delta=0.25 \mathrm{~mm}$, while the outer shell is made of PVC with $32 \mathrm{~mm}$ outer diameter and $28 \mathrm{~mm}$ inner diameter. The total length of double-tube heat exchanger is $1200 \mathrm{~mm}$. Insulating layer covered on the outer tube is adopted to prevent the heat loss. There are two working fluids including thermal fluid (deionized water) and cold fluid $\left(\mathrm{TiO}_{2}-\mathrm{H}_{2} \mathrm{O}\right.$ nanofluids) in the two circulation closed units. The pressure drop and temperatures of the thermal fluid and nanofluids are measured by differential pressure transmitters (type: MIK-3051, pressure measuring range: $0-1 \mathrm{KPa}$ and $0-5 \mathrm{KPa}$ ) and four thermocouples, which are installed in the import and export of the heat exchanger. A date acquisition instrument (type: 34972A, manufacturer: Agilent) is used to collect the temperature date. 

is adopted to keep the cold fluids (nanofluids) temperature constant, and the thermal

212 fluid (deionized water) temperature is regulated by a hot water tank with a thermostat 213 (type: DC-2030A, accuracy: $\pm 0.05^{\circ} \mathrm{C}$ ). And the smooth double-tube heat exchanger only has the difference of inner tube type. In addition, the boundary conditions of the experiments are shown in Table 1. water in the hot water tank, and set the temperature to the desired value.

Fig. 2. The experimental system of the corrugated double-tube heat exchanger The experimental procedure is as follows:

(1) Place the nanofluids in the low-temperature thermostat bath and deionized

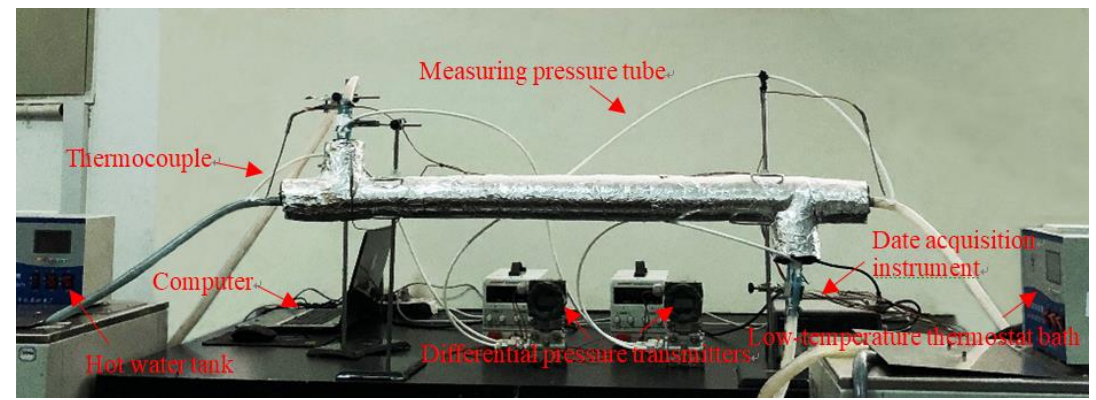

Fig. 1. Schematic diagram of the experimental system 
236 where

experimental system for leakage.

(3) Open the differential pressure transmitters, date acquisition instrument and computer, collect date of the import and export of the two loops, perform more than three experiments on each experimental condition and record the experimental dates.

(4) When the experiment is completed, turn off the high-power thermostat, then turn off the pumps and date acquisition instrument, finally turn off the main power. Table 1 Boundary conditions of the experiment

\begin{tabular}{|c|c|c|c|c|}
\hline Type & \multicolumn{2}{|c|}{ Nanofluids in tube-side } & \multicolumn{2}{|c|}{ Nanofluids in shell-side } \\
\hline Inlet & $20^{\circ} \mathrm{C}$ & $40^{\circ} \mathrm{C}$ & $40^{\circ} \mathrm{C}$ & $20^{\circ} \mathrm{C}$ \\
\hline Temperature & (tube-side) & (shell-side) & (tube-side) & (shell-side) \\
\hline Ranoe & & $q_{v}$ & $q_{v}$ & $R e$ \\
\hline Kange & $3000-12000$ & $1-5 \mathrm{~L} / \mathrm{min}$ & $1-5 \mathrm{~L} / \mathrm{min}$ & $3000-12000$ \\
\hline $\begin{array}{l}\text { Outer wall } \\
\text { (shell) }\end{array}$ & \multicolumn{4}{|c|}{ Insulation wall } \\
\hline $\begin{array}{c}\text { Outer wall } \\
\text { (tube) }\end{array}$ & \multicolumn{4}{|c|}{ Heat transfer surface } \\
\hline
\end{tabular}

\subsection{Experimental data processing}

The average heat exchange capacity from thermal fluid (deionized water) to cold fluid (nanofluids) is defined as:

$$
Q_{\mathrm{ave}}=\frac{Q_{\mathrm{w}}+Q_{\mathrm{nf}}}{2}
$$

$$
\begin{aligned}
& Q_{\mathrm{w}}=m_{\mathrm{w}} c_{\mathrm{pw}}\left(T_{\mathrm{in}}-T_{\text {out }}\right)_{\mathrm{w}} \\
& Q_{\mathrm{nf}}=m_{\mathrm{nf}} c_{\mathrm{pnf}}\left(T_{\text {out }}-T_{\mathrm{in}}\right)_{\mathrm{nf}}
\end{aligned}
$$

The logarithmic mean temperature difference $\Delta T_{\mathrm{m}}$ is evaluated from:

$$
\Delta t_{\mathrm{m}}=\frac{\Delta t_{\max }-\Delta t_{\min }}{\ln \frac{\Delta t_{\max }}{\Delta t_{\min }}}
$$


The overall heat transfer coefficient is expressed as:

$$
h=\frac{Q_{\text {ave }}}{A \Delta T_{\mathrm{m}}}
$$

The effectiveness and the $N T U$ are given by:

\section{Results and discussions}

\subsection{Experimental system validation}
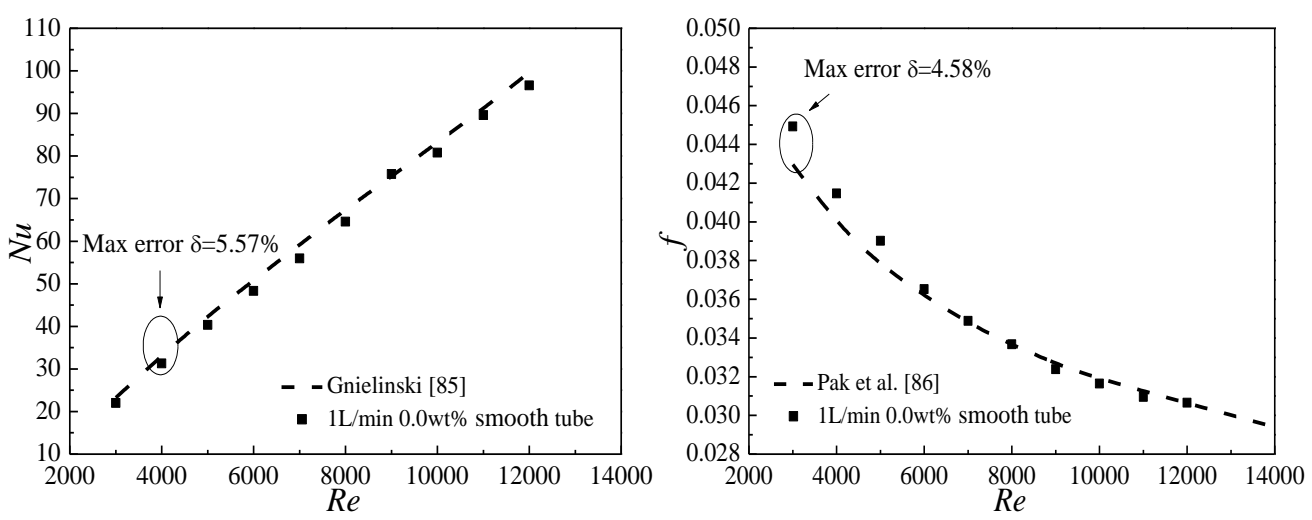

Fig. 3. Comparison between the experimental results and other results in published references, (a) $N u$, (b) $f$

Before beginning to study the characteristics of the thermal performance and

pressure drop, an analysis of the reliability and accuracy of the experimental setup is required. Nusselt number are obtained using "Wilson plots" method [84], and the comparison of the Nusselt number between this experiment and the published reference [85] is shown in Fig 3(a). It can be found that the experimental results are in 
good agreement with the published reference, and the maximum difference between them is around 5.57\%. Fig. 3 also shows the resistance coefficient comparison between this experiment and published reference [86]. Results show that the errors are within $4.58 \%$. The above studies can verify the reliability and accuracy of this experimental system.

\subsection{Error analysis}

Based on the root-sum-square method presented by Kline [87], the errors of physical parameters can be calculated from following equations (9-11), and the results are shown in Table 2. It is indicated that the maximum uncertainties in the resistance coefficient, $N T U$ and effectiveness are $\pm 1.18 \%, \pm 1.77 \%$, and $\pm 2.06 \%$ respectively.

$$
\begin{gathered}
\frac{\delta N T U}{N T U}=\sqrt{\left(\frac{\delta Q}{Q}\right)^{2}+\left(\frac{\delta l}{l}\right)^{2}+\left(\frac{\delta m}{m}\right)^{2}+\left(\frac{\delta T}{T}\right)^{2}} \\
\frac{\delta \varepsilon}{\varepsilon}=\sqrt{\left(\frac{\delta N T U}{N T U}\right)^{2}+\left(\frac{\delta m}{m}\right)^{2}} \\
\frac{\delta f}{f}=\sqrt{\left(\frac{\delta \Delta p}{\Delta p}\right)^{2}+\left(\frac{\delta l}{l}\right)^{2}+\left(\frac{\delta m}{m}\right)^{2}}
\end{gathered}
$$

Table 2 Errors of each section in the experiment

\begin{tabular}{cccccccc}
\hline$\delta Q / Q$ & $\delta T / T$ & $\delta \Delta p / \Delta p$ & $\delta l / l$ & $\delta m / m$ & $\delta N T U / N T U$ & $\delta \varepsilon / \varepsilon$ & $\Delta f / f$ \\
$\pm 1.0 \%$ & $\pm 1.0 \%$ & $\pm 0.5 \%$ & $\pm 0.1 \%$ & $\pm 1.06 \%$ & $\pm 1.77 \%$ & $\pm 2.06 \%$ & $\pm 1.18 \%$ \\
\hline
\end{tabular}

\subsection{Experimental results and discussions}

\subsubsection{Shell-side water and tube-side nanofluids}

In the experimental study of the smooth and corrugated double-tube heat exchangers, the heat transfer medium in tube-side is $\mathrm{TiO}_{2}-\mathrm{H}_{2} \mathrm{O}$ nanofluids with different mass fractions $\omega=0.0 \%, 0.1 \%, 0.3 \%$ and $0.5 \%$, and the inlet temperature is $20^{\circ} \mathrm{C}$. The shell-side working fluid is the thermal fluid (deionized water) with an inlet temperature of $40^{\circ} \mathrm{C}$. The Reynolds numbers of the nanofluids range from 3000 to 
experiment.

\subsubsection{Heat transfer rate}

Fig. 4 and Fig. 5 show the influence of Nanofluids mass fraction on the heat transfer rate of smooth and corrugated double-tube heat exchangers, and Fig. 6 is a summary graph on the heat transfer rate changes with velocity.
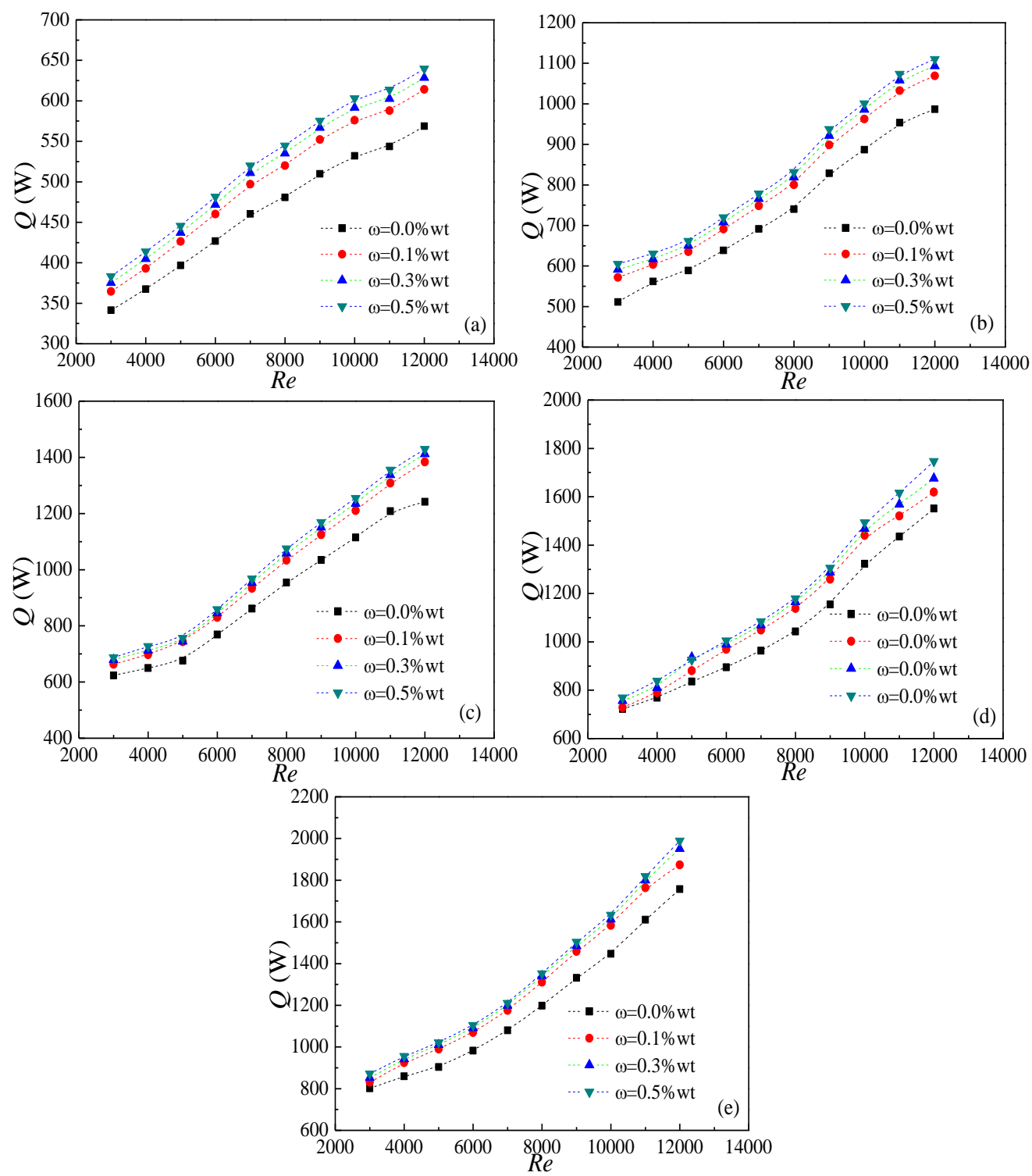

Fig. 4. Effects of nanoparticle mass fraction on the heat transfer rate of the smooth double-tube heat exchanger, (a) $q_{v}=1 \mathrm{~L} / \mathrm{min}$, (b) $q_{v}=2 \mathrm{~L} / \mathrm{min}$, (c) $q_{v}=3 \mathrm{~L} / \mathrm{min}$, (d)

$$
q_{v}=4 \mathrm{~L} / \mathrm{min}, \text { (e) } q_{v}=5 \mathrm{~L} / \mathrm{min}
$$

It is indicated that the increase of Reynolds number (velocity) promotes the 

compared to deionized water [88].
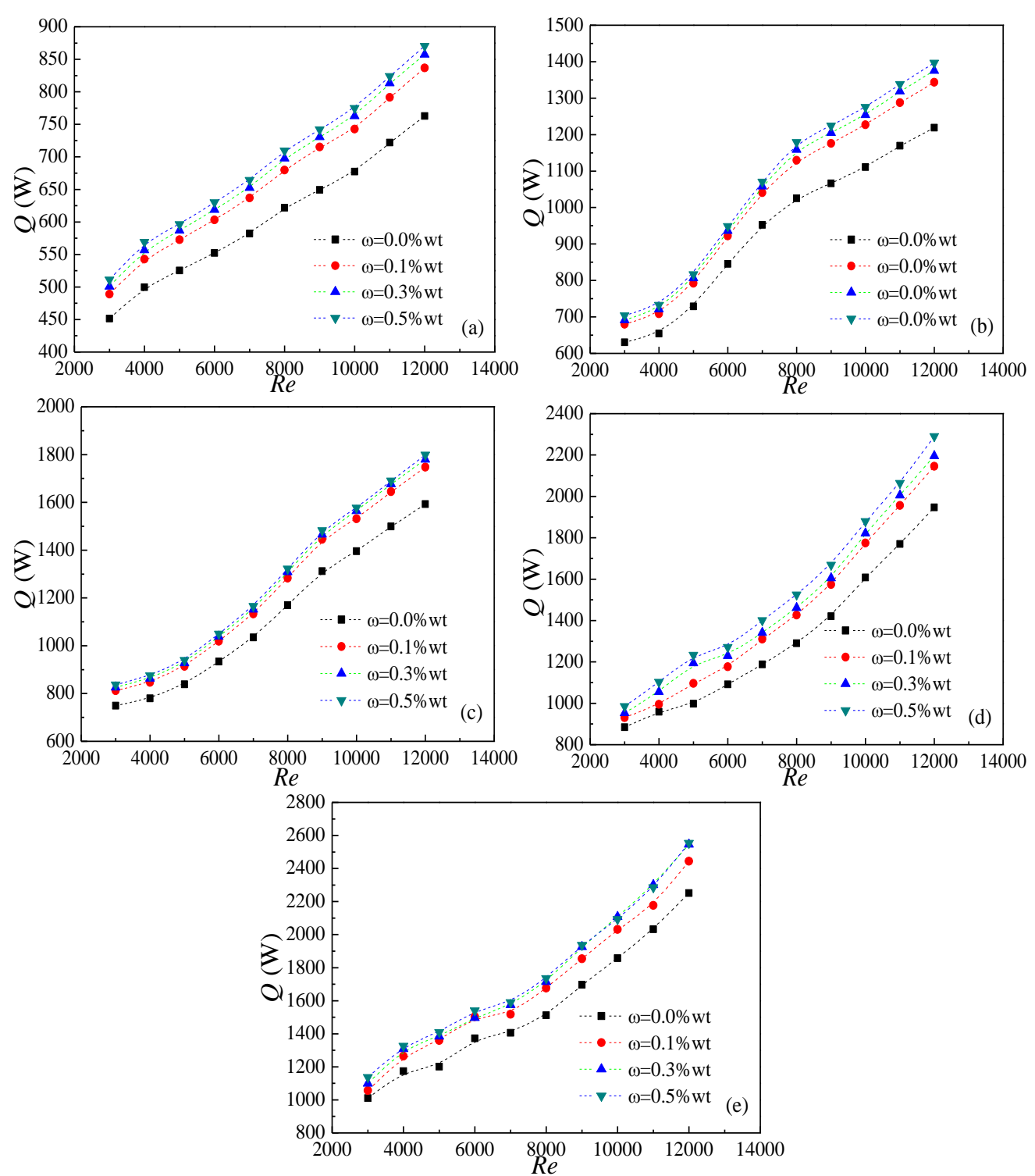

Fig. 5. Effects of nanoparticle mass fraction on the heat transfer rate of the corrugated double-tube heat exchanger, (a) $q_{v}=1 \mathrm{~L} / \mathrm{min}$, (b) $q_{v}=2 \mathrm{~L} / \mathrm{min}$, (c) $q_{v}=3 \mathrm{~L} / \mathrm{min}$, (d)

$$
q_{v}=4 \mathrm{~L} / \mathrm{min}, \text { (e) } q_{v}=5 \mathrm{~L} / \mathrm{min}
$$



is indicated that the increase of thermal fluid flow rate promotes the increase of the heat transfer rate. However, the enhanced heat transfer capacity of nanofluids shows slightly larger compared with deionized water when the thermal fluid flow rates are larger. The heat transfer rate of nanofluids is improved slightly with the increase of the thermal fluid flow rate.

In the smooth double-tube heat exchanger, take $\omega=0.1 \%$ as an example, the heat transfer rate can be improved by $8.29 \%, 8.56 \%, 8.7 \%, 9.13 \%$ and $9.49 \%$ at best compared with deionized water when the volume flow rates range from $1 \mathrm{~L} / \mathrm{min}$ to condition. 

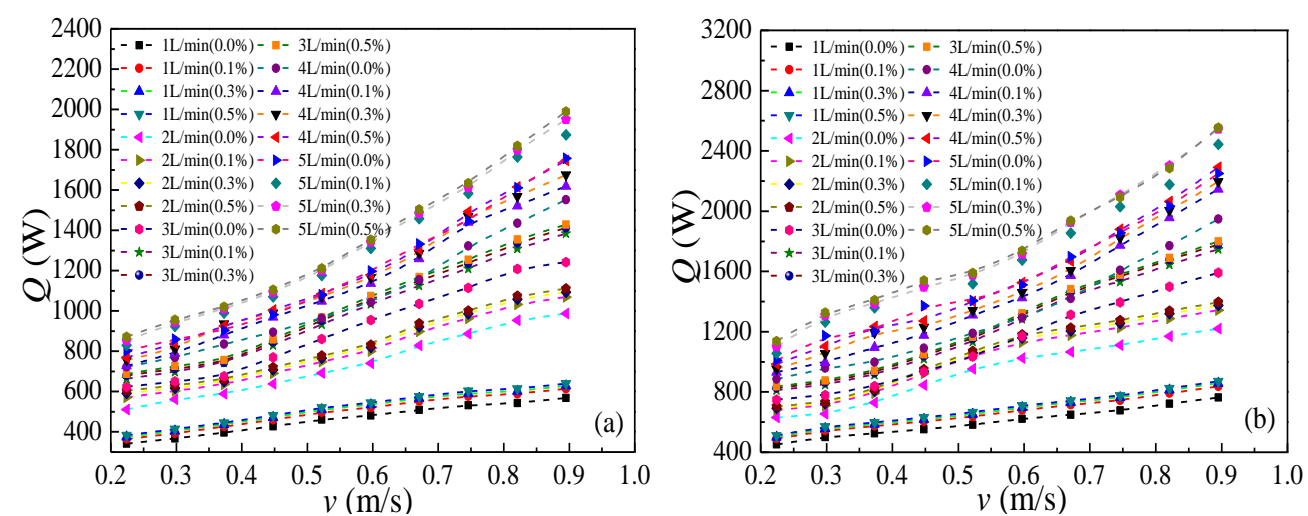

Fig. 6. The summary graph on the heat transfer rate with velocity, (a) smooth tube, (b) 3.3.1.2 NTU corrugated tube

In a heat exchanger, the main indexes for the thermal performance are the number of transfer units (NTU) and effectiveness. Hence, the two enhancement indexes will be analyzed and discussed in the following section.

Fig. 7 and Fig. 8 show the variations of $N T U$ in the smooth and corrugated double-tube heat exchangers, and Fig. 9 is a summary graph on $N T U$ with velocity. As displayed in Fig. 7 and Fig. 8, the trends of the NTU are more diverse compared with Fig. 4 and Fig. 5. NTU shows the effects of the relationship between the flow rates of the thermal fluid and cold fluid on the overall thermal performance of the heat exchanger, so its value is also related to the relative flow rates of the two kinds of working fluids.

When the thermal fluid flow rates are $1 \mathrm{~L} / \mathrm{min}$ and $2 \mathrm{~L} / \mathrm{min}$, as the Reynolds number increases, the $N T U$ of the two kinds of double-tube heat exchangers all increases. But when volume flow rates are from $3 \mathrm{~L} / \mathrm{min}$ to $5 \mathrm{~L} / \mathrm{min}$, the $N T U$ shows a trend of decreasing firstly and then increases. This phenomenon can be explained by formula (6). From formula (6), it can be found that the $N T U$ is related to the minimum flow rates of the nanofluids and thermal fluid. The thermal fluid flow rate in the 

cold fluid flow rate is greater than the thermal fluid flow rate, in theory, the lowest point occurs when the two fluids flow rate are the same. And as displayed in Figs. 7-8 (c), (d) and (e), as the flow rate of thermal fluid increases, the NTU shows a downward trend and the lowest point also moves toward the high Reynolds number.
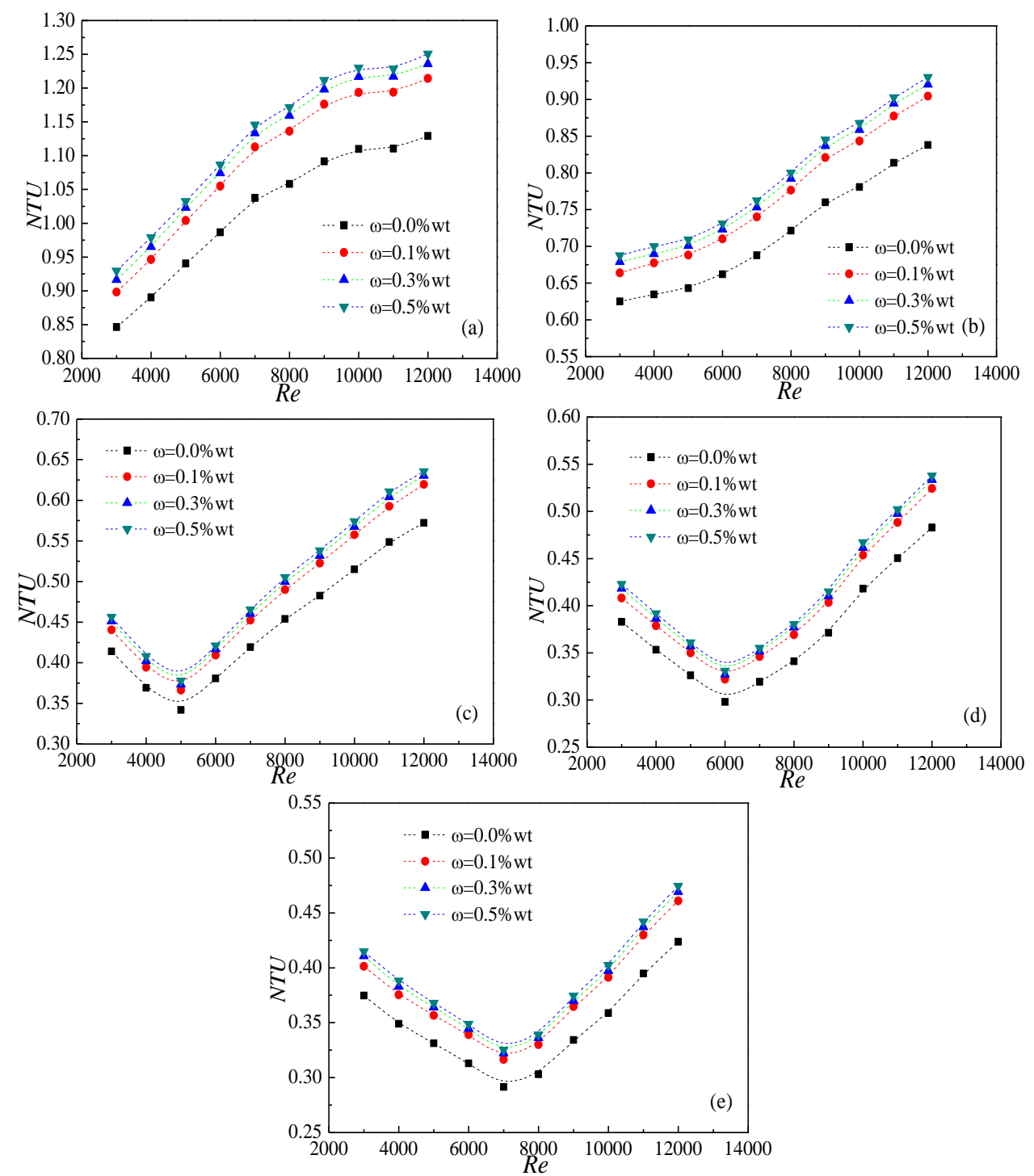

Fig. 7. Effects of nanoparticle mass fraction on $N T U$ of the smooth double-tube heat exchanger, (a) $q_{v}=1 \mathrm{~L} / \mathrm{min}$, (b) $q_{v}=2 \mathrm{~L} / \mathrm{min}$, (c) $q_{v}=3 \mathrm{~L} / \mathrm{min}$, (d) $q_{v}=4 \mathrm{~L} / \mathrm{min}$, (e)

$$
q_{v}=5 \mathrm{~L} / \mathrm{min}
$$

Furthermore, with the increase of the nanofluids mass fraction, the $N T U$ also 

best under the same condition.
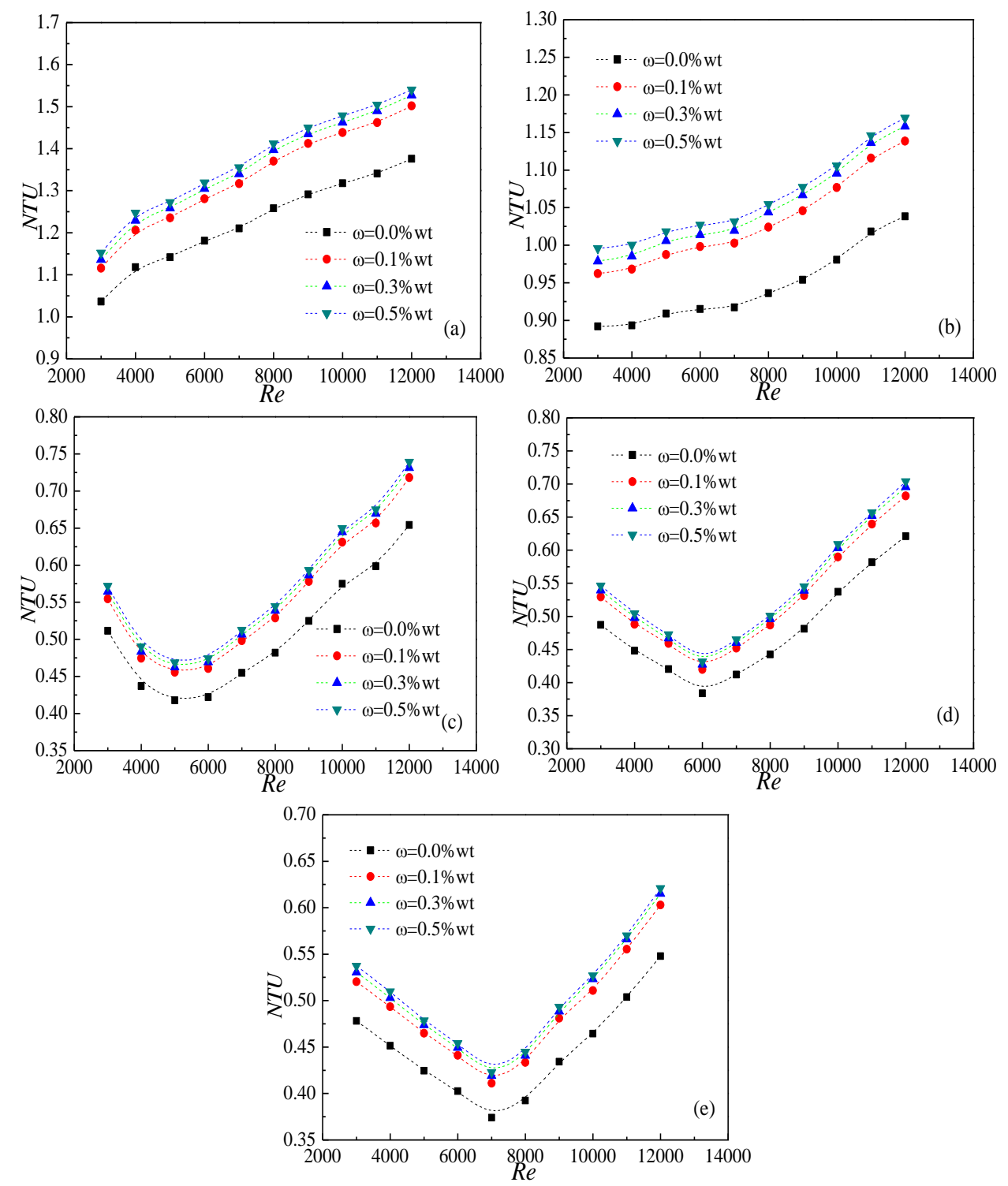

Fig. 8. Effects of nanoparticle mass fraction on $N T U$ of the corrugated double-tube 

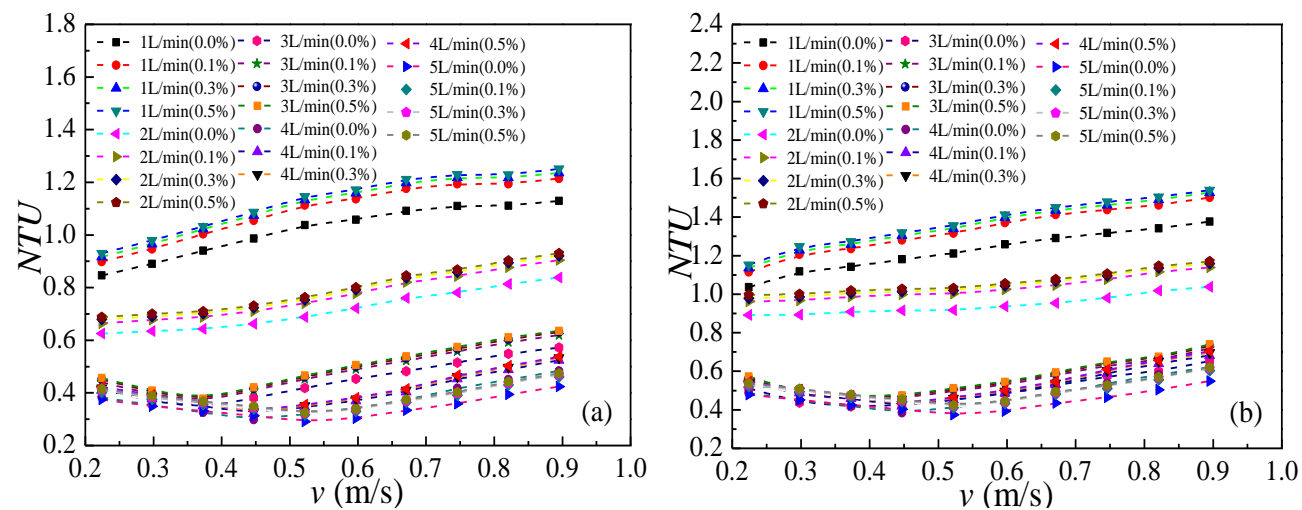

Fig. 9. The summary graph on the $N T U$ with velocity, (a) smooth tube, (b) corrugated

\subsubsection{Effectiveness}

tube

Effectiveness shows a similar trend with $N T U$. Fig. 10 and Fig. 11 show the influence of nanofluids mass fraction and the thermal fluid volume flow rates on the effectiveness of the smooth and corrugated double-tube heat exchangers respectively, and Fig. 12 is a summary graph on effectiveness changes with velocity. It is indicated that when the thermal fluid flow rate is larger, the effectiveness decreases, which means that when the Reynolds number of nanofluids is constant, increasing the thermal fluid volume flow rate can improve the heat transfer rate, but it does not necessarily improve the effectiveness. This phenomenon can make the industry to obtain the actual thermal performance required by adjusting the flow rates of thermal fluid and nanofluids.

Under the strengthening effect of nanofluids, the effectiveness of the two kinds of double-tube heat exchangers has been improved. Taking the thermal fluid in shell-side with a volume flow rate of 5L/min and a Reynolds number of 9000 in tube-side as an example, it can be found that $\mathrm{TiO}_{2}-\mathrm{H}_{2} \mathrm{O}$ nanofluids with $\omega=0.1 \%, 0.3 \%$ and $0.5 \%$ can improve the effectiveness from $31.1 \%$ to $33.4 \%, 33.8 \%$ and $34.1 \%$ respectively compared with deionized water. 

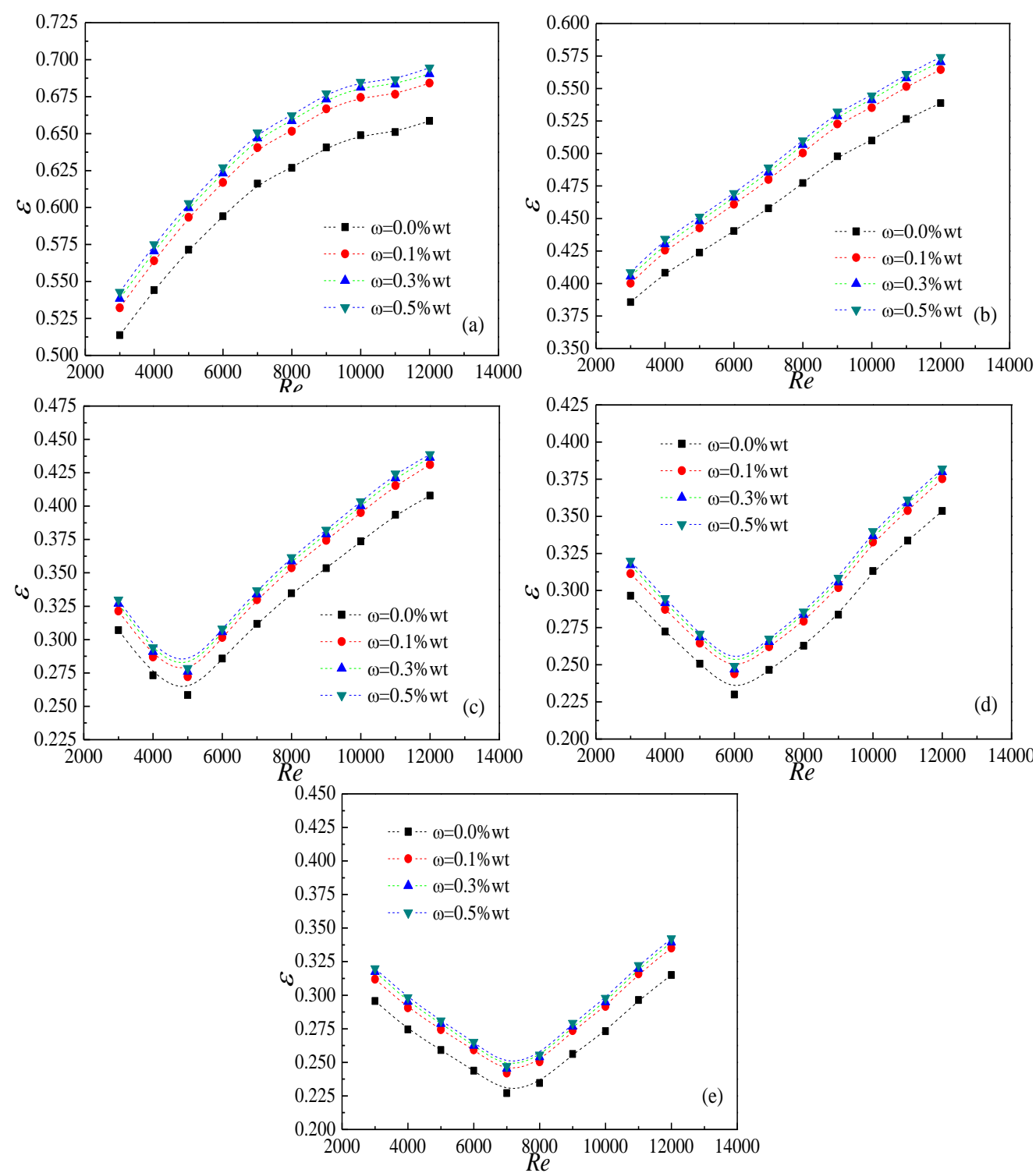

Fig. 10. Effects of nanoparticle mass fraction on the effectiveness of the smooth double-tube heat exchanger, (a) $q_{v}=1 \mathrm{~L} / \mathrm{min}$, (b) $q_{v}=2 \mathrm{~L} / \mathrm{min}$, (c) $q_{v}=3 \mathrm{~L} / \mathrm{min}$, (d)

$$
q_{v}=4 \mathrm{~L} / \mathrm{min},(\mathrm{e}) q_{v}=5 \mathrm{~L} / \mathrm{min}
$$

At the same time, this section takes the volume flow rates (from $1 \mathrm{~L} / \mathrm{min}$ to 5L/min) in shell-side and a Reynolds number of 9000 in tube-side as an example, The intuitive comparative analysis on the effectiveness in the smooth and corrugated double-tube heat exchangers is studied. Compared with deionized water in the smooth double-tube heat exchanger, the effectiveness of nanofluids in the corrugated double-tube heat exchanger is improved from $64.1 \%, 49.8 \%, 35.3 \%, 28.3 \%, 25.6 \%$ to $73.8 \%, 61.2 \%, 40.9 \%, 37.5 \%, 34.1 \%$ respectively. It is obtained that the nanoparticles 

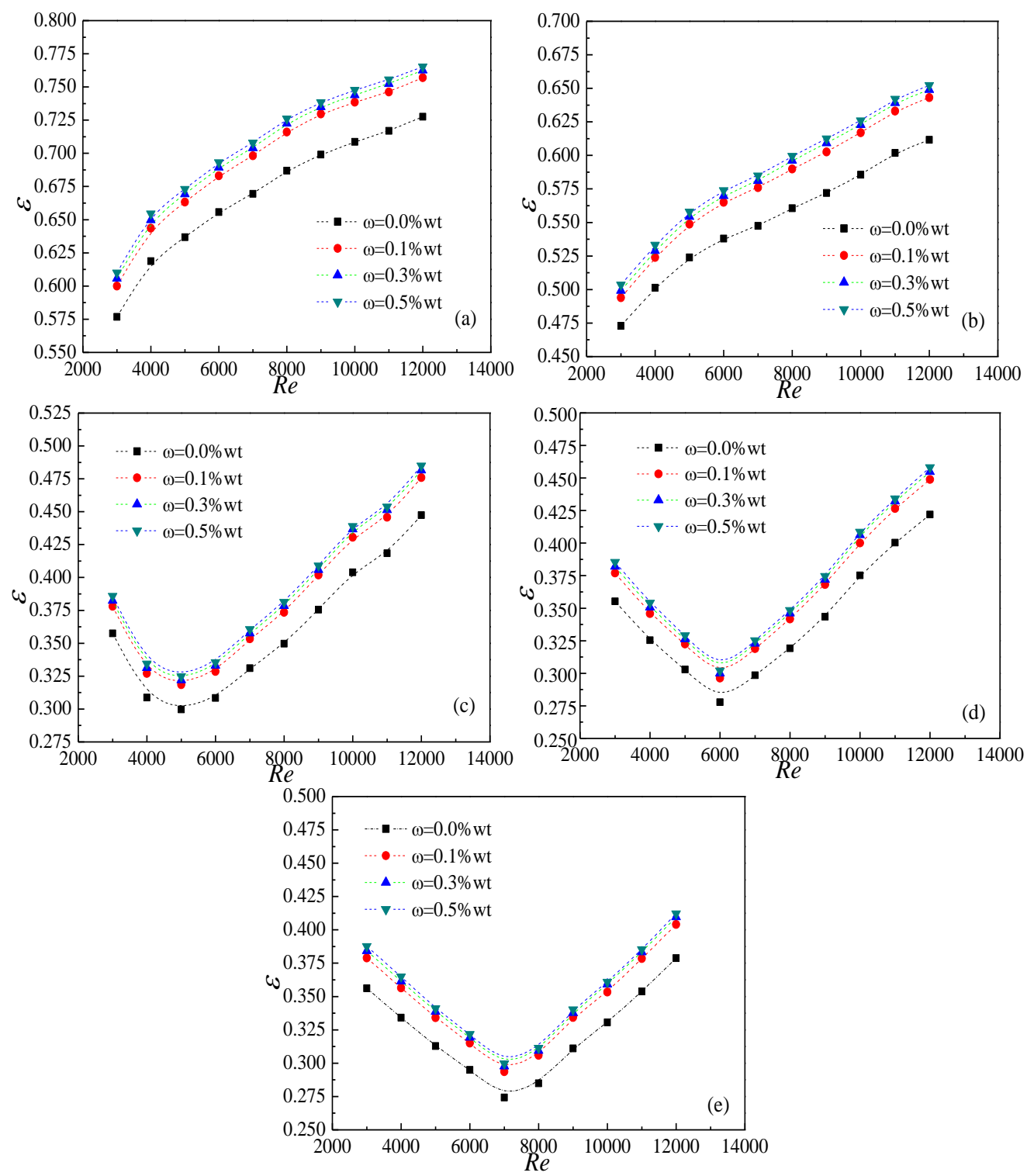

Fig. 11. Effects of nanoparticle mass fraction on the effectiveness of the corrugated double-tube heat exchanger, (a) $q_{v}=1 \mathrm{~L} / \mathrm{min}$, (b) $q_{v}=2 \mathrm{~L} / \mathrm{min}$, (c) $q_{v}=3 \mathrm{~L} / \mathrm{min}$, (d)

$$
q_{v}=4 \mathrm{~L} / \mathrm{min}, \text { (e) } q_{v}=5 \mathrm{~L} / \mathrm{min}
$$
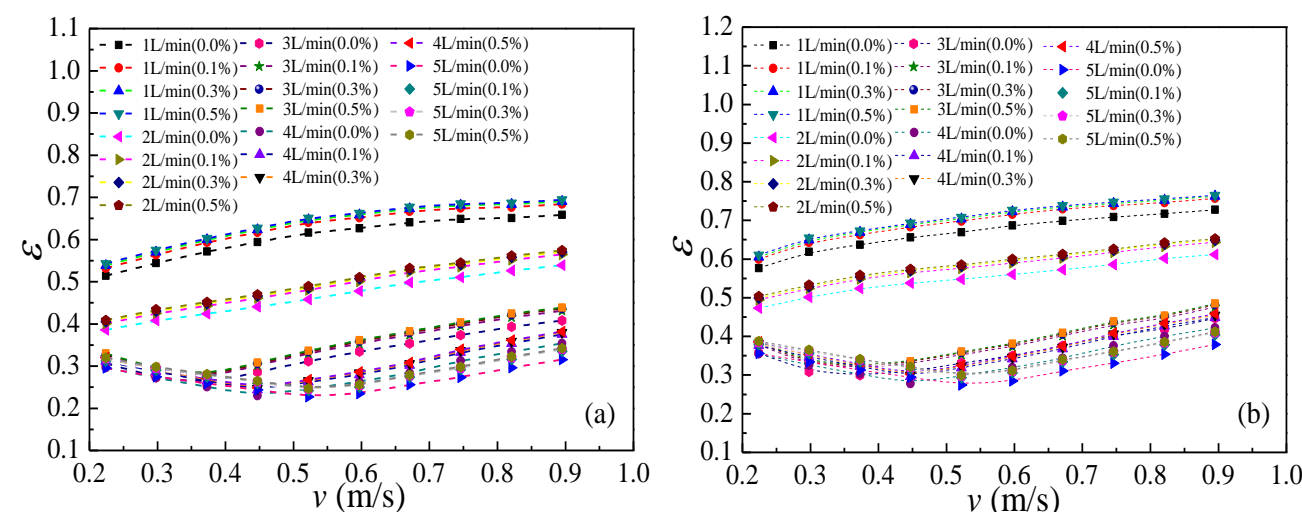

Fig. 12. The summary graph on the effectiveness with velocity, (a) smooth tube, (b) 

significantly higher than the traditional smooth tube and deionized water.

417

418

\subsubsection{Pressure drop}

For the practical application of nanofluids, studying the flow and heat transfer performances is inevitable. Adding nanoparticles into base fluid can improve the heat conductivity, but it also increases the flow resistance. This section will discuss the pressure drop of nanofluids in tube-side.
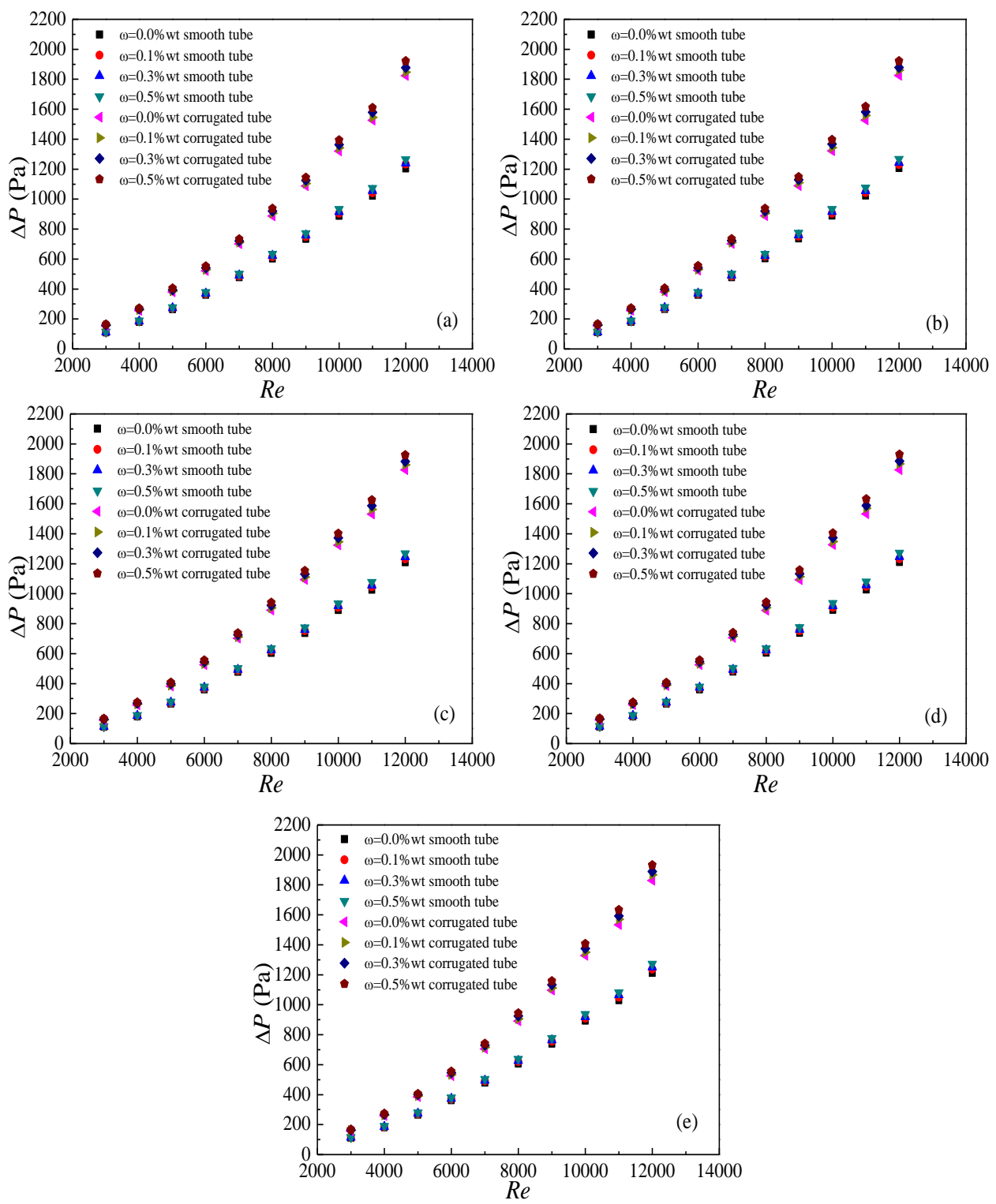

Fig. 13. Effects of nanoparticle mass fraction on the pressure drop of the two kinds of double-tube heat exchangers, (a) $q_{v}=1 \mathrm{~L} / \mathrm{min}$, (b) $q_{v}=2 \mathrm{~L} / \mathrm{min}$, (c) $q_{v}=3 \mathrm{~L} / \mathrm{min}$, (d)

$$
q_{v}=4 \mathrm{~L} / \mathrm{min},(\mathrm{e}) q_{v}=5 \mathrm{~L} / \mathrm{min}
$$



concentrations, which can be explained by that the addition of the nanoparticles increases the friction-induced property, namely, dynamic viscosity. Compared with deionized water, the pressure drop of nanofluids with $\omega=0.1 \%, 0.3 \%$ and $0.5 \%$ is improved by $2.77 \%, 4.38 \%$ and $6.5 \%$ at best respectively in the corrugated

double-tube heat exchanger. Furthermore, Fig. 13 also shows that the different thermal fluid flow rates in shell-side hardly have effect on the pressure drop of nanofluids, which is because the thermal fluid belongs to the shell-side circuit, and the fluid flow states of thermal fluid and nanofluids do not affect each other.

When comparing the pressure drop of two kinds of double-tube heat exchangers, Fig. 13 shows that the pressure drop in the corrugated tube is significantly stronger, and under the same conditions, it can be increased by $51.9 \%$ at best compared with that of the smooth tube.

\subsubsection{Comprehensive performance analysis}

There are many indexes for evaluating the comprehensive performance of heat exchanger, and PEC evaluation method is widely used, but it is troublesome to calculate the Nusselt number of the all experimental conditions. Therefore, EEC (efficiency evaluation criterion) is obtained as the comprehensive evaluation criteria in this experiment, and the calculation equation is as follows [89]:

$$
E E C=\frac{Q / Q_{0}}{(V \Delta P) /\left(V_{0} \Delta P_{0}\right)}
$$

In the formula, $Q$ represents the amount of heat exchange rate, and $V$ represents the volume flow rate. The $Q / Q_{0}$ and the $(V \Delta P) /\left(V_{0} \Delta P_{0}\right)$ represent the ratio of thermal 
transfer and the pump power consumption between the enhanced tube and the smooth tube respectively. Therefore, the EEC is also a comprehensive indicator of heat exchangers (thermal efficiency).

Deionized water with the smallest mass flow rate $\left(q_{v}=1 \mathrm{~L} / \mathrm{min}\right)$ shows the lowest thermal performance, in order to investigate the largest heat transfer enhancement ratio, other working conditions are all compared with deionized water with $q_{v}=1 \mathrm{~L} / \mathrm{min}$. According to the EEC formula, this experiment compares of nanofluids (all the experimental conditions $)$ and deionized water $\left(q_{v}=1 \mathrm{~L} / \mathrm{min}\right)$ in the smooth double-tube heat exchanger. The comparison results are shown in Fig. 14(a). At the same time, all the experimental conditions in the corrugated double-tube heat exchanger are also compared with deionized water $\left(q_{v}=1 \mathrm{~L} / \mathrm{min}\right)$ in the smooth double-tube heat exchanger. The comparison results are shown in Fig. 14(b).
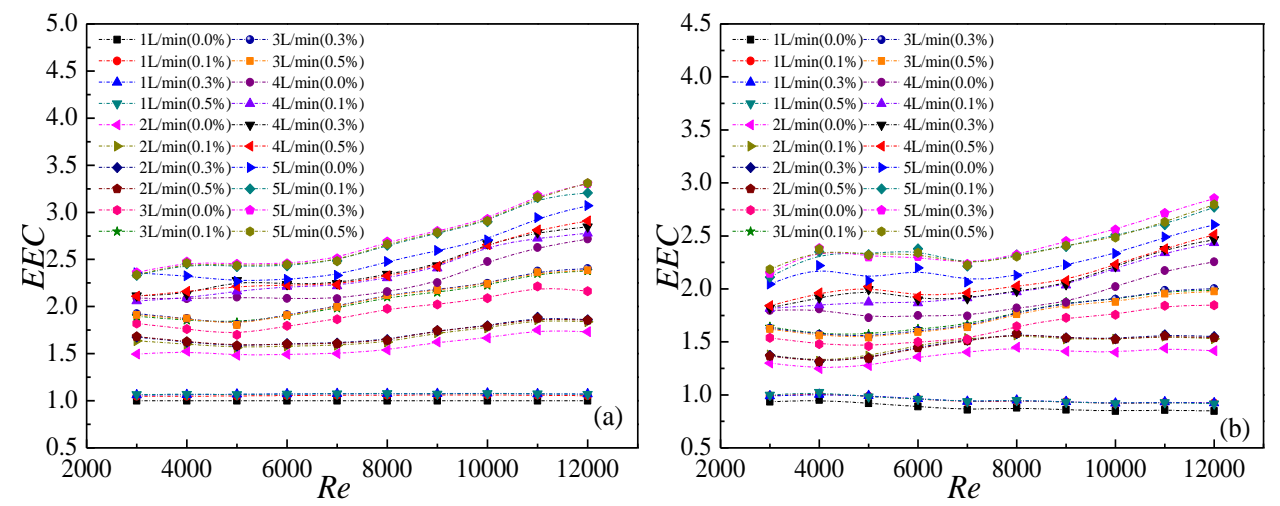

Fig. 14. Comprehensive performance analysis of the tube-side nanofluids, (a) smooth tube, (b) corrugated tube

Fig. 14 manifests that the maximum comprehensive evaluation coefficients in the smooth double-tube heat exchanger are 1.78, 1.885, 2.4, 2.91 and 3.31 respectively when the volume flow rates of thermal fluid are from $1 \mathrm{~L} / \mathrm{min}$ to $5 \mathrm{~L} / \mathrm{min}$. And the maximum comprehensive evaluation coefficients in the corrugated double-tube heat exchanger are $1.025,1.576,2.01,2.51$ and 2.85 respectively when the thermal fluid 
471 comprehensive evaluation coefficient of the smooth and corrugated heat exchangers,

472 it is indicated that the maximum comprehensive evaluation coefficient is lower in the

473 corrugated double-tube heat exchanger under the same conditions. The reason is that

474 in the condition of thermal fluid in shell-side and nanofluids in tube-side, although the

475 corrugated tube can disturb the fluid to improve the heat exchange capacity, the

476 pressure drop significantly increases, hence, the comprehensive performance index of

477 the corrugated double-tube heat exchanger is lower. Therefore, this layout (thermal

478 fluid in shell-side and nanofluids in tube-side) is not the best choice to obtain the best

479 comprehensive performance of the combination of corrugated tube and nanofluids.

$480 \quad$ 3.3.2 Shell side-nanofluids and tube side-water

481 The smooth and corrugated double-tube heat exchangers (nanofluids in shell-side and thermal fluid (deionized-water) in tube-side) are experimentally studied in this

483 section respectively. The working fluids in shell-side are $\mathrm{TiO}_{2}-\mathrm{H}_{2} \mathrm{O}$ nanofluids with different mass fractions $(\omega=0.0 \mathrm{wt} \%, 0.1 \mathrm{wt} \%, 0.3 \mathrm{wt} \%$ and $0.5 \mathrm{wt} \%)$, the inlet temperature is $20^{\circ} \mathrm{C}$, and the Reynolds numbers range from 3000 to 12000 . The working fluid in tube-side is thermal fluid (deionized water) with different volume

487 flow rates $\left(q_{v}=1-5 \mathrm{~L} / \mathrm{min}\right)$, and the inlet temperature is $40^{\circ} \mathrm{C}$.

\subsubsection{Heat transfer rate}

Fig. 15 and Fig. 16 show the effects of nanoparticle mass fractions and different 

turbulence. Furthermore, with the increase of nanofluids concentrations, the heat transfer rate increases, and it can be also improved by the increase of the thermal fluid flow rate, and these experimental phenomena are basically consistent with the experimental conclusions in the previous experiment. However, compared with the previous experiment, the heat transfer rate (nanofluids in shell-side and thermal fluid in tube-side) is stronger that of (nanofluids in tube-side and thermal fluid in
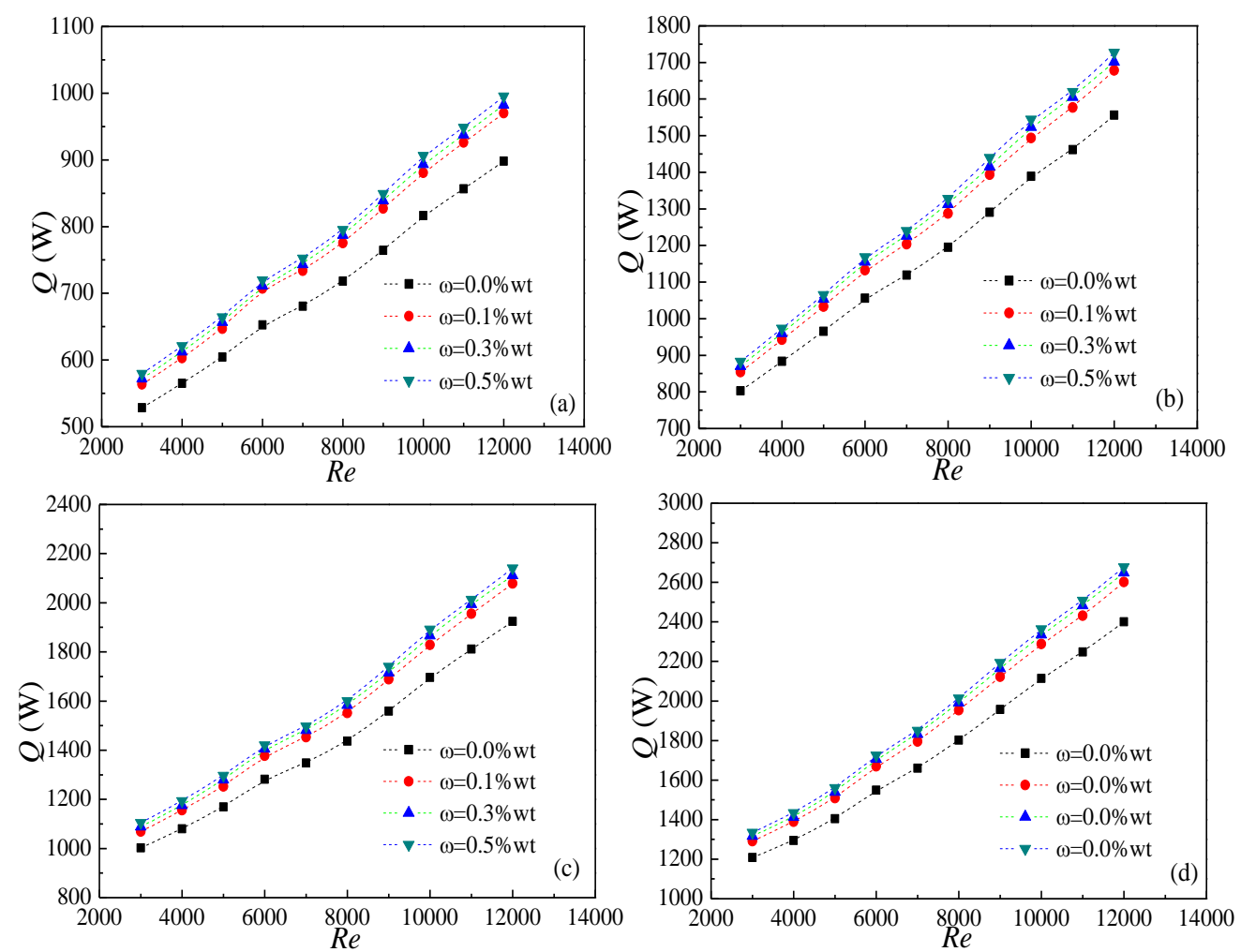

501

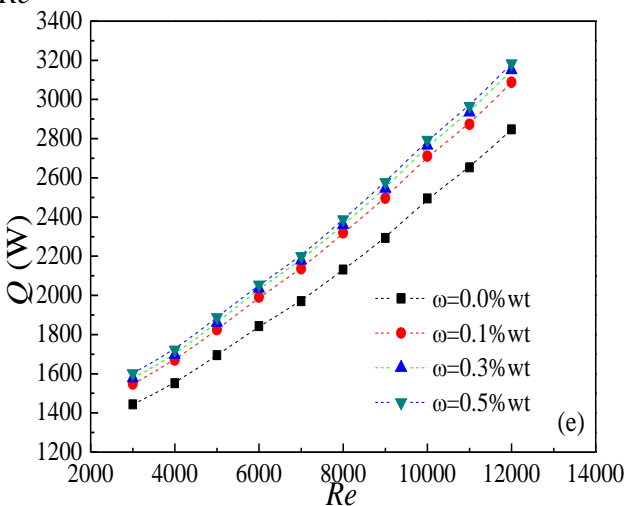

Fig. 15. Effects of nanoparticle mass fraction on the heat transfer rate of the smooth double-tube heat exchanger, (a) $q_{v}=1 \mathrm{~L} / \mathrm{min}$, (b) $q_{v}=2 \mathrm{~L} / \mathrm{min}$, (c) $q_{v}=3 \mathrm{~L} / \mathrm{min}$, (d)

$$
q_{v}=4 \mathrm{~L} / \mathrm{min}, \text { (e) } q_{v}=5 \mathrm{~L} / \mathrm{min}
$$


508 leads to the improvement of the heat transfer rate.
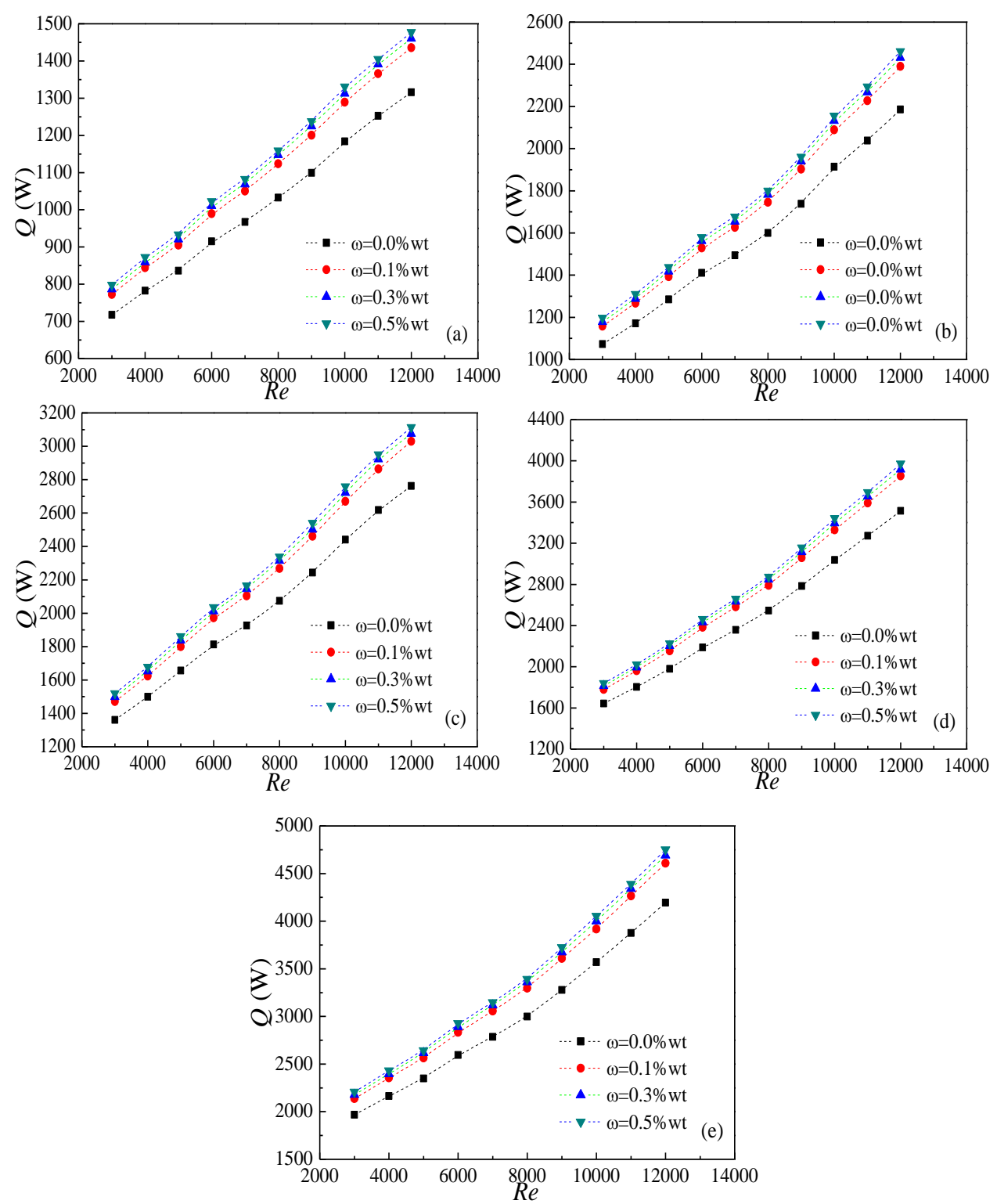

heat exchanger is stronger, and it can be improved by $49.2 \%$ at best compared with smooth inner tube under the same condition. Furthermore, it can be also improved by 
518

519

$10.08 \%, 12.1 \%$ and $13.6 \%$ at best using nanofluids with $\omega=0.1 \mathrm{wt} \%, 0.3 \mathrm{wt} \%$ and $0.5 \mathrm{wt} \%$ compared with deionized water respectively. Compared the maximum thermal enhancement of nanofluids with the previous experiment, it is indicated that nanofluids with $\omega=0.1 \%, 0.3 \%$ and $0.5 \%$ in this experiment have lower heat transfer enhancement. This is mainly because the corrugated tube used in the experiment has a greater disturbance in the tube-side than that in the shell-side, furthermore, the larger flow rate also causes the collision and friction frequency between the solid nanoparticles and the heat transfer surface to be weak when nanofluids flow in the shell-side.
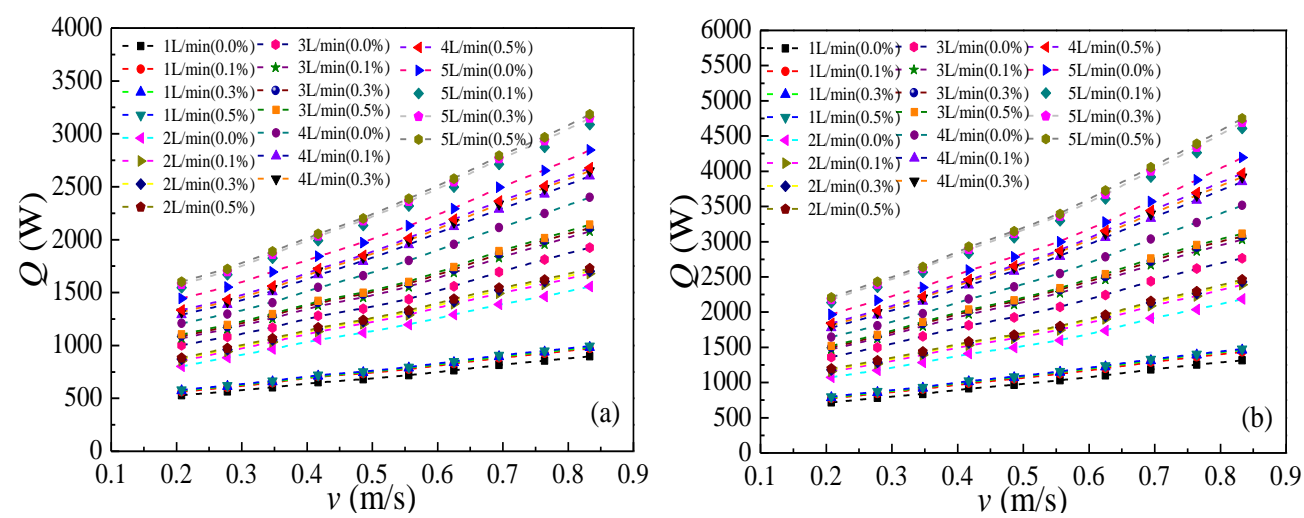

Fig. 17. The summary graph on the heat transfer rate with velocity, (a) smooth tube, (b)

\subsubsection{NTU} corrugated tube

In a heat exchanger, the $N T U$ and effectiveness are two important indicators for evaluating the overall thermal performance. The $N T U$ results of smooth and corrugated double-tube heat exchangers are demonstrated in Fig. 18 and Fig. 19 respectively. The summary graph on the NTU with velocity is shown in Fig. 20.

The $N T U$ trends of this experiment don't show a tendency to increase firstly and then decrease. This can be explained that the flow rate of nanofluids in the shell-side is larger than that in the tube-side under the same Reynolds number, the $N T U$ is 

shell-side and tube-side.
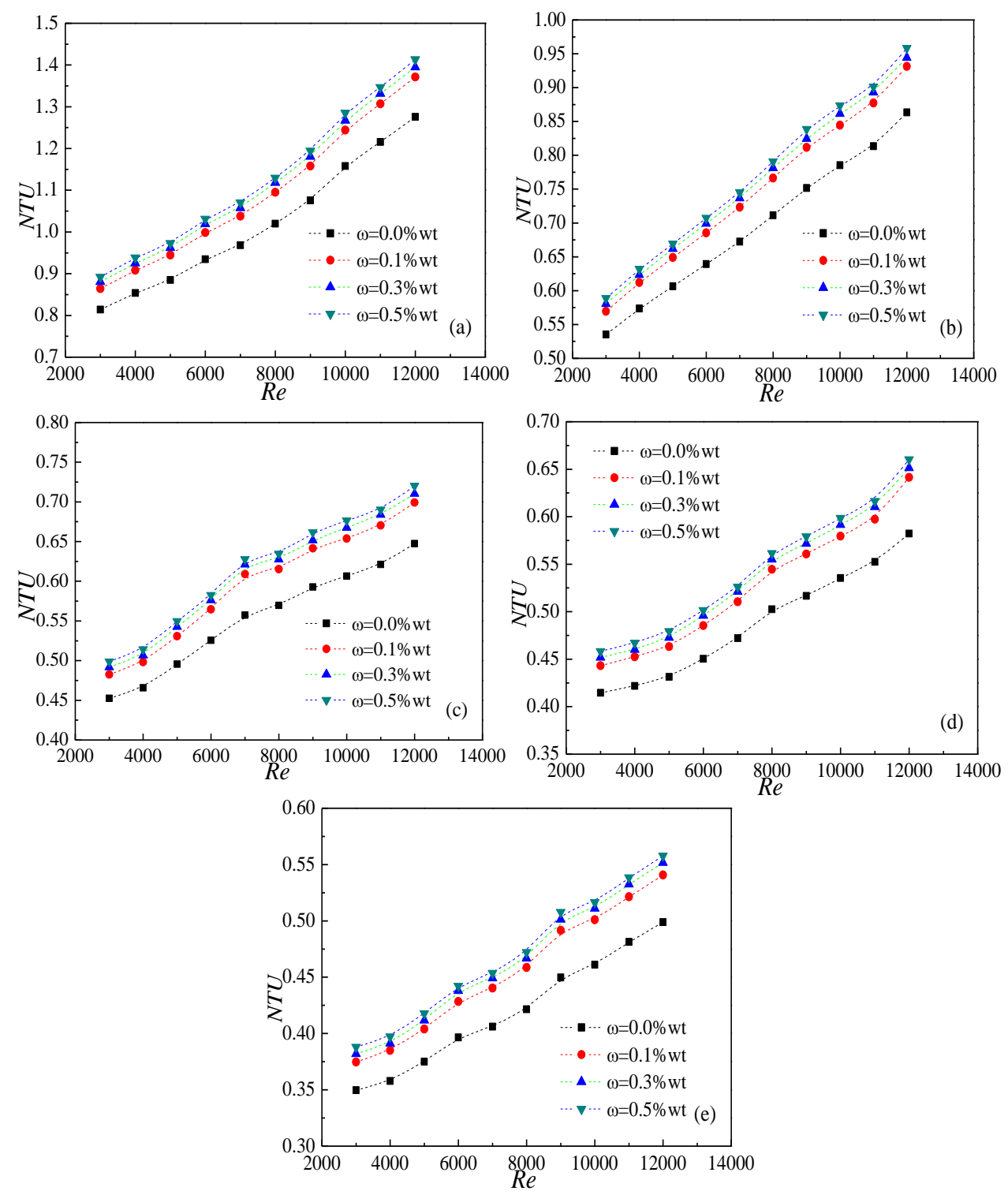

Fig. 18. Effects of nanoparticle mass fraction on $N T U$ of the smooth double-tube heat exchanger, (a) $q_{v}=1 \mathrm{~L} / \mathrm{min}$, (b) $q_{v}=2 \mathrm{~L} / \mathrm{min}$, (c) $q_{v}=3 \mathrm{~L} / \mathrm{min}$, (d) $q_{v}=4 \mathrm{~L} / \mathrm{min}$, (e)

$$
q_{v}=5 \mathrm{~L} / \mathrm{min}
$$

Figs. 18-20 also show that when the thermal fluid volume flow rate is constant, as the Reynolds number in shell-side increases, the $N T U$ also increases correspondingly. Increasing Reynolds number in shell-side can significantly improve the thermal performance at this time. Furthermore, under the same thermal fluid flow rate, the $N T U$ can be improved by $42.8 \%$ at best in the corrugated double-tube heat 
exchanger.
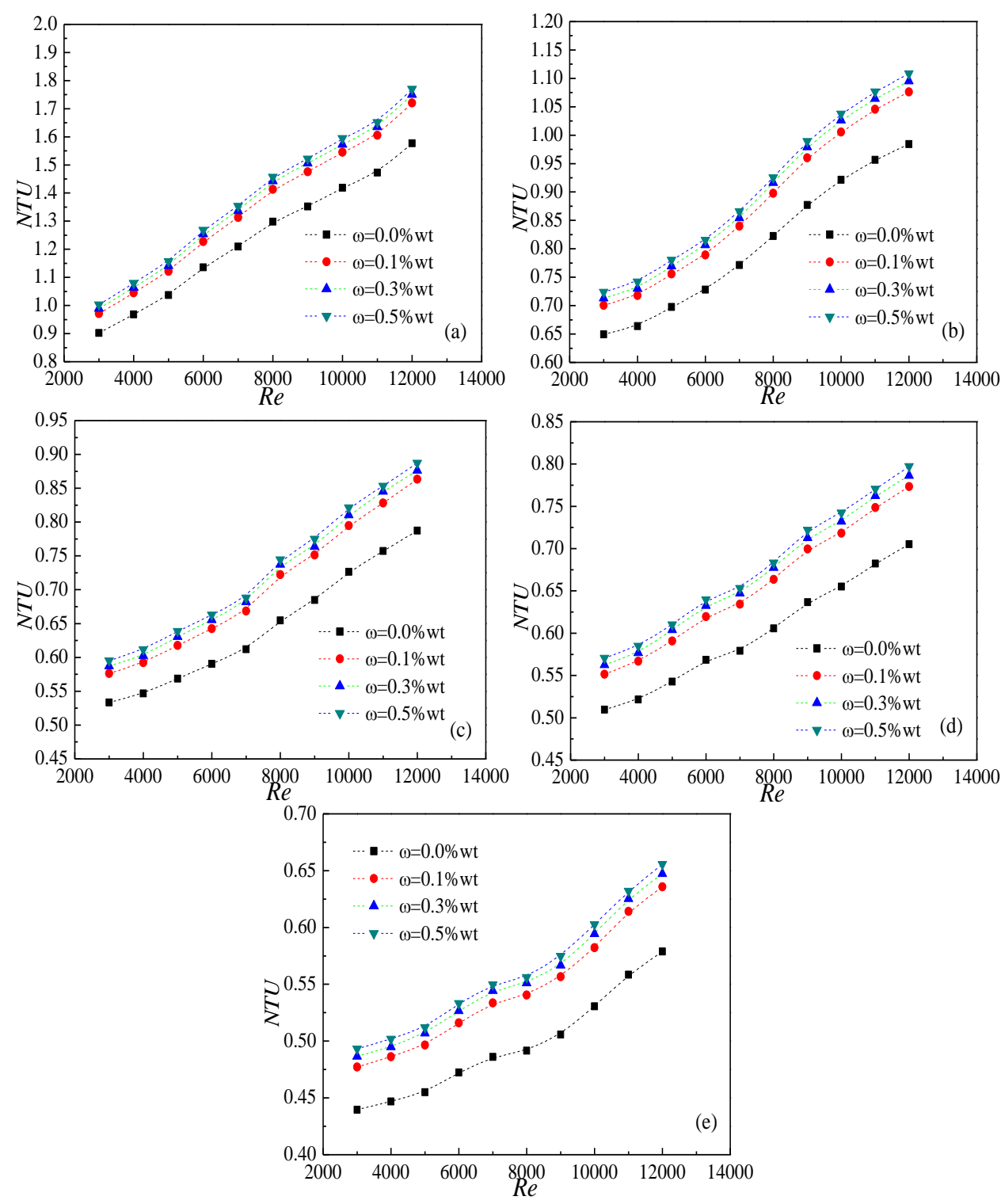

Fig. 19. Effects of nanoparticle mass fraction on $N T U$ of the corrugated double-tube $q_{v}=5 \mathrm{~L} / \mathrm{min}$
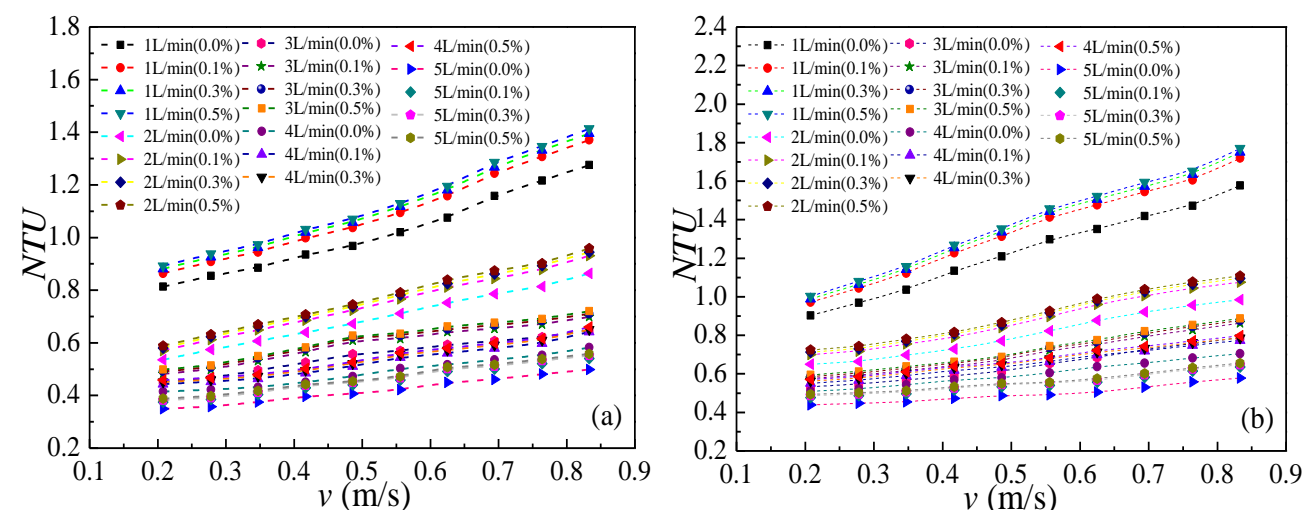

Fig. 20. The summary graph on the $N T U$ with velocity, (a) smooth tube, (b) 


\subsubsection{Effectiveness}

The variations of effectiveness against Reynolds number in shell-side are depicted in Fig. 21 and Fig. 22, and the summary graph on the effectiveness with velocity is shown in Fig. 23. The influence of different nanoparticle mass fractions and thermal fluid flow rates on the effectiveness is discussed. With the increase of the nanofluids concentration and Reynolds number, the effectiveness increases correspondingly. And the effectiveness is stronger in the corrugated double-tube heat
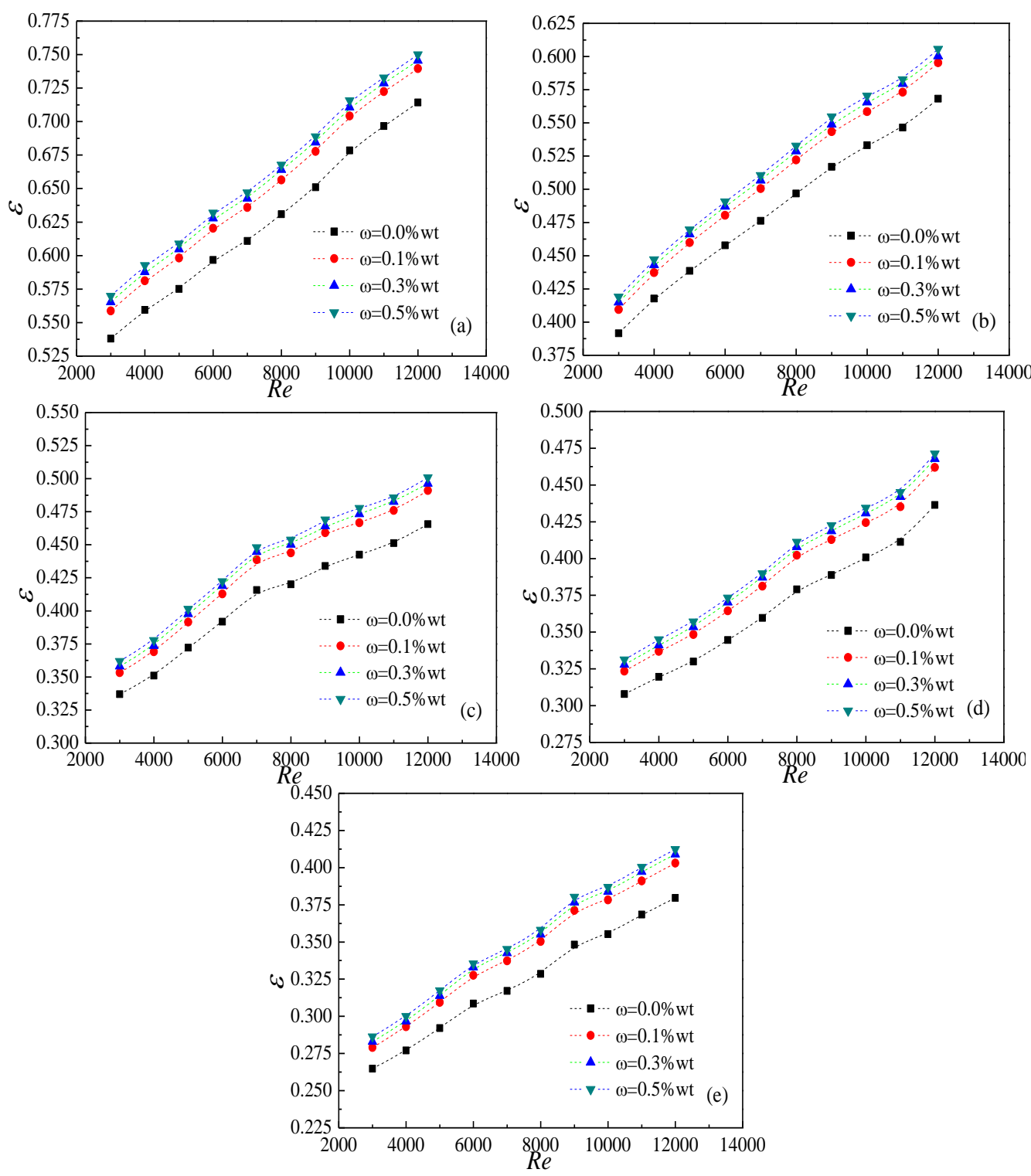

Fig. 21. Effects of nanoparticle mass fraction on the effectiveness of the smooth double-tube heat exchanger, (a) $q_{v}=1 \mathrm{~L} / \mathrm{min}$, (b) $q_{v}=2 \mathrm{~L} / \mathrm{min}$, (c) $q_{v}=3 \mathrm{~L} / \mathrm{min}$, (d) $q_{v}=4 \mathrm{~L} / \mathrm{min},(\mathrm{e}) q_{v}=5 \mathrm{~L} / \mathrm{min}$ 
exchanger under the same condition.

In order to intuitively express the influence of the nanofluids concentration on the effectiveness, this experiment takes the flow rate in tube-side $q_{\mathrm{v}}=5 \mathrm{~L} / \mathrm{min}$ and Reynolds number in shell-side $R e=9000$ as an example for comparative analysis. When the working medium in shell-side is deionized water, the effectiveness of the corrugated double-tube heat exchanger is $37.9 \%$, and the effectiveness of nanofluids with $\omega=0.1 \mathrm{wt} \%, 0.3 \mathrm{wt} \%$ and $0.5 \mathrm{wt} \%$ can reach $40.6 \%, 41.2 \%$ and $41.6 \%$
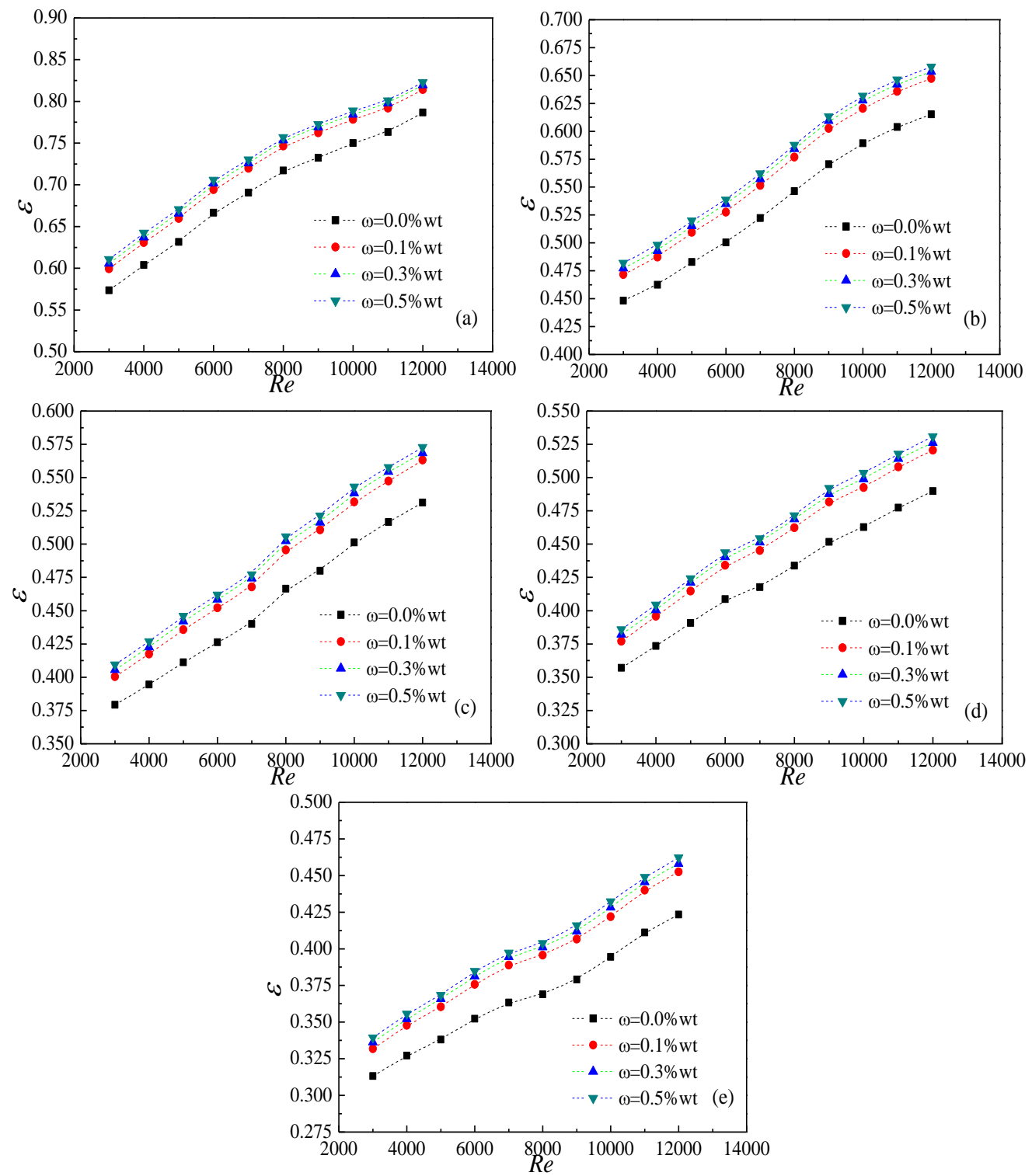

Fig. 22. Effects of nanoparticle mass fraction on the effectiveness of the corrugated double-tube heat exchanger, (a) $q_{v}=1 \mathrm{~L} / \mathrm{min}$, (b) $q_{v}=2 \mathrm{~L} / \mathrm{min}$, (c) $q_{v}=3 \mathrm{~L} / \mathrm{min}$, (d)

$$
q_{v}=4 \mathrm{~L} / \mathrm{min} \text {, (e) } q_{v}=5 \mathrm{~L} / \mathrm{min}
$$


respectively.

Furthermore, intuitive comparative analysis of the effectiveness of two kinds of double-tube heat exchangers can be also obtained from Figs. 21-23. This experiment takes the volume flow rates in tube-side (from $1 \mathrm{~L} / \mathrm{min}$ to $5 \mathrm{~L} / \mathrm{min}$ ) and the Reynolds number in shell-side $R e=9000$ as an example, for the combination of deionized water and smooth double-tube heat exchanger, the effectiveness can reach $65.1 \%, 51.7 \%$, $43.4 \%, 38.8 \%$ and $34.8 \%$ under different volume flow rates respectively. For the combination of nanofluids and corrugated double-tube heat exchanger, the effectiveness can reach $77.2 \%, 61.3 \%, 52.1 \%, 49.2 \%$ and $41.6 \%$ under different thermal fluid flow rates respectively. From the comparison, it can be found that although the effectiveness decreases with the thermal fluid flow rate, the combination of the corrugated tube and nanofluids can obviously improve the effectiveness of the double-tube heat exchangers.
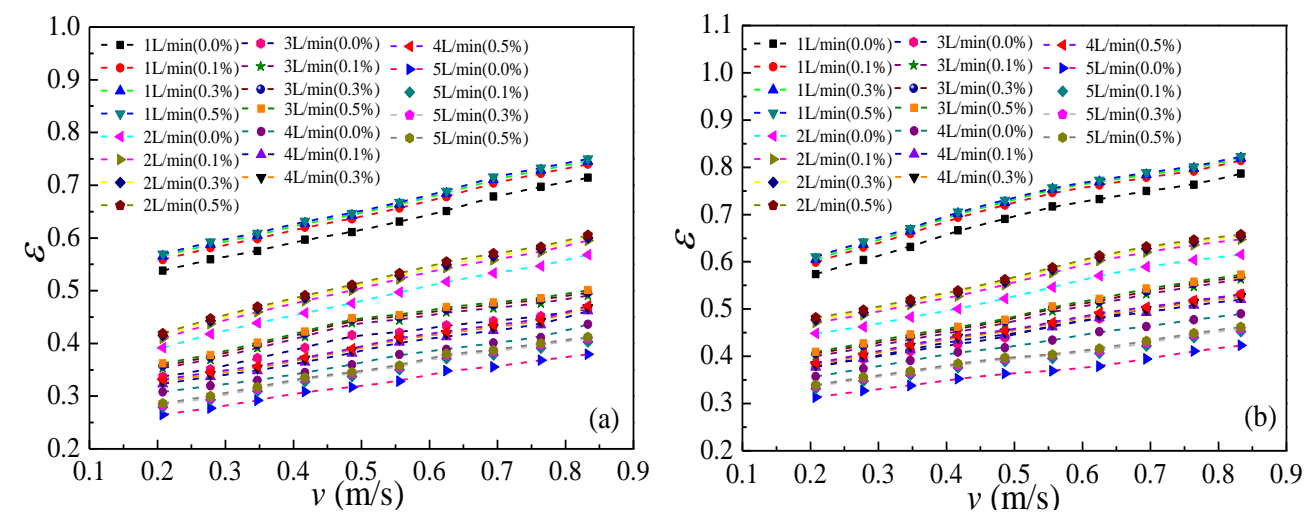

Fig. 23. The summary graph on the effectiveness with velocity, (a) smooth tube, (b)

\subsubsection{Pressure drop} corrugated tube

In the experiment of this section, the shell-side working fluid is nanofluids. Therefore, in the smooth and corrugated double-tube heat exchangers, this experiment mainly studies the variation of the shell-side pressure drop. Fig. 24 presents the 
with each other.


Fig. 24. Effects of nanoparticle mass fraction on the drop pressure in shell-side of the smooth and corrugated double-tube heat exchangers, (a) $q_{v}=1 \mathrm{~L} / \mathrm{min}$, (b) $q_{v}=2 \mathrm{~L} / \mathrm{min}$, (c) 
620 double-tube heat exchanger, it is indicated that the pressure drop in the corrugated double-tube heat exchanger is significantly stronger, and the maximum increase in pressure drop can reach $40.7 \%$ under the same thermal fluids flow rate, which also shows that the increase is smaller than that of the previous experiment.

Furthermore, the viscosity of the nanofluids is higher than that of the deionized water, so that the nanofluids have a greater flow resistance than the deionized water. In the corrugated double-tube heat exchanger, the pressure drop of nanofluids with $\omega=0.1 \mathrm{wt} \%, 0.3 \mathrm{wt} \%$ and $0.5 \mathrm{wt} \%$ is improved by $2.77 \%, 3.89 \%$ and $5.97 \%$ at best compared with deionized water respectively. Therefore, the influence of the nanoparticle concentration on the pressure drop is smaller than the disturbance of the corrugated tube.

\subsubsection{Comprehensive performance analysis}

The EEC formula in this section considers the heat transfer rate and the shell-side pressure drop. Fig. 25(a) compares all experimental conditions of nanofluids $(\omega=0.0 \mathrm{wt} \%, 0.1 \mathrm{wt} \%, 0.3 \mathrm{wt} \%$ and $0.5 \mathrm{wt} \%)$ in the smooth double-tube heat exchanger with deionized water $\left(q_{v}=1 \mathrm{~L} / \mathrm{min}\right)$ in the smooth double-tube heat exchanger. Fig. 25(b) provides a comprehensive comparison between all experimental conditions of nanofluids $(\omega=0.0 \mathrm{wt} \%, 0.1 \mathrm{wt} \%, 0.3 \mathrm{wt} \%$ and $0.5 \mathrm{wt} \%)$ in the corrugated double-tube heat exchanger and deionized water $\left(q_{v}=1 \mathrm{~L} / \mathrm{min}\right)$ in the smooth double-tube heat exchanger. Fig. 25(a) presents that when the thermal fluid flow rates are from $1 \mathrm{~L} / \mathrm{min}$ to $5 \mathrm{~L} / \mathrm{min}$, the maximum $E E C$ values are $1.06,1.79,2.27,2.84$ and 3.37 respectively. In Fig. 25(b), the maximum EEC values are 1.15, 1.88, 2.38, 3.01 
642

643

644

646

647

648

649

650

651

652

653

654

655

656

657

658

659

660

661

and 3.56 respectively. It can be intuitively seen from the $E E C$ that when the flow pattern of the thermal fluid in tube-side and nanofluids in shell-side is selected, the maximum comprehensive performance index of nanofluids and corrugated tube combination is stronger than that of nanofluids and smooth tube combination under the same thermal fluid flow rate. Therefore, the selection of the nanofluids flowing in the shell-side can not only reflect the heat transfer enhancement of the nanofluids, but also reflect the thermal performance of the corrugated tube.
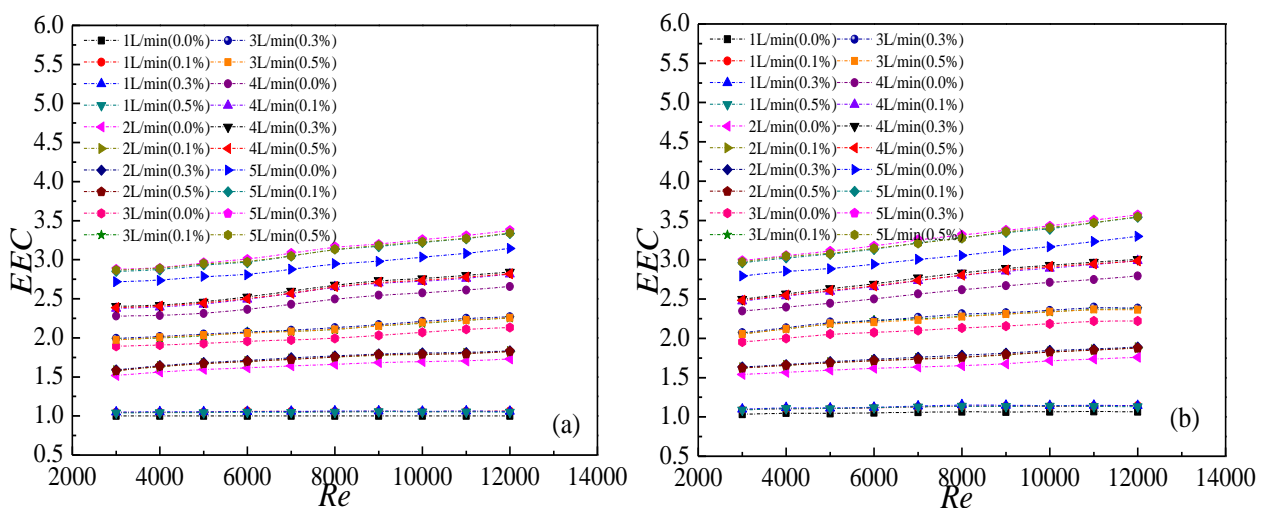

Fig. 25. Comprehensive performance analysis of nanofluids in the shell-side, (a) smooth tube, (b) corrugated tube

The comparative analysis of this experiment and the previous experiment are studied. In the previous experiment, it has been concluded that when the nanofluids flow in the tube-side, the pressure drop of nanofluids can be improved by $51.9 \%$ at best. However, when the nanofluids flow in the shell-side, the pressure drop can be improved by $40.7 \%$ at best. Furthermore, nanofluids flow in the shell-side can also have a greater heat transfer rate, which is mainly due to the less contact with the external environment, and when the Reynolds number of the nanofluids is kept constant, nanofluids flowing in the shell-side will have a larger flow rate, then the heat transfer rate becomes larger. Therefore, regardless of the actual application, or the comparison of comprehensive performance, the choice of thermal fluid in the 
662

663

664

665

666

667

668

669

670

671

672

673

674

675

676

677

678

679

680

681

682

683

tube-side and nanofluids in the shell-side will be more appropriate.

\section{Conclusion}

The thermal performance and pressure drop of nanofluids in the smooth and corrugated double-tube heat exchangers are experimentally investigated, and the experimental results are compared between these two kinds of double-tube heat exchangers. Some main conclusions are obtained as follows:

(1) $\mathrm{TiO}_{2}-\mathrm{H}_{2} \mathrm{O}$ nanofluids with $\omega=0.1 \mathrm{wt} \%, 0.3 \mathrm{wt} \%$ and $0.5 \mathrm{wt} \%$ have better thermal performance than the deionized water, the heat transfer rate can be improved by $10.8 \%, 13.4 \%$ and $14.8 \%$ at best respectively, and the pressure drop of nanofluids can be increased by $2.77 \%, 4.38 \%$ and $6.5 \%$ at best respectively.

(2) The thermal performance of the corrugated double-tube heat exchanger is significantly stronger than that of the same size smooth double-tube heat exchanger. But the pressure drop of nanofluids in the corrugated double-tube heat exchanger is also significantly stronger, and it can be increased by $51.9 \%$ (tube-side) and $40.7 \%$ (shell-side) at best.

(3) When using both nanofluids and corrugated tube, the overall thermal performance is significantly enhanced, which reflects in the increase of the NTU and effectiveness. $N T U$ can be improved by $47.5 \%$ at best. However, for thermal fluid in the shell-side, the $N T U$ and effectiveness decrease firstly and then increase with the increase of Reynolds number.

(4) When nanofluids flow in the tube-side, the comprehensive performance index of the corrugated tube is lower than that of the smooth tube under the same 
684

685

686

687

688

689

690

691

692

693

694

695

696

697

698

699

700

701

702

703

704

705

conditions.

(5) When nanofluids flow in the shell-side, the comprehensive performance index is stronger than that of the smooth tube under the same condition. Therefore, in practical applications, it is more reasonable to select the flow mode of thermal fluid in the tube-side and nanofluids in the shell-side.

\section{Acknowledgements}

This work is financially supported by "National Natural Science Foundation of China" (Grant No. 51606214), "Natural Science Foundation of Jiangsu Province, China" (Grant No. BK20181359) and "EU ThermaSMART project, H2020-MSCA-RISE (778104)-Smart thermal management of high power microprocessors using phase-change (ThermaSMART)".

\section{References}

[1] Sajid MU, Ali HM. Thermal conductivity of hybrid nanofluids: A critical review. Int J Heat Mass Transf 2018; 126: 211-234.

[2] Ranjbarzadeh R, Moradikazerouni A, Bakhtiari R, Asadi A, Afrand M. An experimental study on stability and thermal conductivity of water/silica nanofluid: Eco-friendly production of nanoparticles. J Clean Prod 2019; 206: 1089-1100.

[3] Asadi A, Pourfattah F. Heat transfer performance of two oil-based nanofluids containing $\mathrm{ZnO}$ and $\mathrm{MgO}$ nanoparticles; a comparative experimental investigation. Powder Technol 2019; 343: 296-308.

[4] Esfahani NN, Toghraie D, Afrand M. A new correlation for predicting the thermal conductivity of $\mathrm{ZnO}-\mathrm{Ag}(50 \%-50 \%) /$ water hybrid nanofluid: An experimental 
study. Powder Technol 2018; 323: 367-373.

707

[5] Esfe MH, Esfandeh S, Afrand M, Rejvani M, Rostamian SH. Experimental evaluation, new correlation proposing and ANN modeling of thermal properties of EG based hybrid nanofluid containing ZnO-DWCNT nanoparticles for internal combustion engines applications. Appl Therm Eng 2018; 133: 452-463.

[6] Safaei MR, Hajizadeh A, Afrand M, Qi C, Yarmand H, Zulkifli NWBM. Evaluating the effect of temperature and concentration on the thermal conductivity of $\mathrm{ZnO}-\mathrm{TiO}_{2} / \mathrm{EG}$ hybrid nanofluid using artificial neural network and curve fitting on experimental data. Physica A 2019; 519: 209-216.

[7] Asadi A, Asadi M, Rezaniakolaei A, Rosendahl LA, Wongwises S. An experimental and theoretical investigation on heat transfer capability of $\mathrm{Mg}$ $(\mathrm{OH})_{2}$ /MWCNT-engine oil hybrid nano-lubricant adopted as a coolant and lubricant fluid. Appl Therm Eng 2018; 129: 577-586.

[8] Asadi A, Aberoumand S, Moradikazerouni A, Pourfattah F, Żyła G, Estelle P, Mahian O, Wongwises S, Nguyen HM, Arabkoohsar A. Recent advances in preparation methods and thermophysical properties of oil-based nanofluids: A state-of-the-art review. Powder Technol 2019; 352: 209-226.

[9] Asadi A. A guideline towards easing the decision-making process in selecting an effective nanofluid as a heat transfer fluid. Energy Convers Manage 2018; 175 : $1-10$.

[10]Zeng J, Xuan Y. Tunable full-spectrum photo-thermal conversion features of magnetic-plasmonic $\mathrm{Fe}_{3} \mathrm{O}_{4} / \mathrm{TiN}$ nanofluid. Nano Energy 2018; 51: 754-763. 
728

729

730

731

732

733

734

735

736

737

738

739

740

741

742

743

744

745

[11]Liu X, Xuan Y. Full-spectrum volumetric solar thermal conversion via photonic nanofluids. Nanoscale 2017; 9(39): 14854-14860.

[12]Li H, He Y, Wang C, Wang X, Hu Y. Tunable thermal and electricity generation enabled by spectrally selective absorption nanoparticles for photovoltaic/thermal applications. Appl Energy 2019; 236: 117-126.

[13] Shi L, He Y, Wang X, Hu Y. Recyclable photo-thermal conversion and purification systems via $\quad \mathrm{Fe}_{3} \mathrm{O}_{4} @ \mathrm{TiO}_{2}$ nanoparticles. Energy Convers Manage 2018; 171: 272-278.

[14]Shi L, He Y, Huang Y, Jiang B. Recyclable $\mathrm{Fe}_{3} \mathrm{O}_{4} @ \mathrm{CNT}$ nanoparticles for high-efficiency solar vapor generation. Energy Convers Manage 2017; 149: 401-408.

[15]Wang X, He Y, Cheng G, Shi L, Liu X, Zhu J. Direct vapor generation through localized solar heating via carbon-nanotube nanofluid. Energy Convers Manage 2016; 130: 176-183.

[16]Liu X, Wang X, Huang J, Cheng G, He Y. Volumetric solar steam generation enhanced by reduced graphene oxide nanofluid. Appl Energy 2018; 220: 302-312.

[17]Wang X, He Y, Liu X. Synchronous steam generation and photodegradation for clean water generation based on localized solar energy harvesting. Energy Convers Manage 2018; 173: 158-166.

[18]Fan LW, Li JQ, Wu YZ, Zhang L, Yu ZT. Pool boiling heat transfer during quenching in carbon nanotube (CNT)-based aqueous nanofluids: Effects of length 
and diameter of the CNTs. Appl Therm Eng 2017; 122: 555-565.

751

752

753

754

755

756

757

758

759

760

761

762

763

764

765

766

767

768

769

770

771

[19]Fan LW, Yao XL, Wang X, Wu YY, Liu XL, Xu X, Yu ZT. Non-isothermal crystallization of aqueous nanofluids with high aspect-ratio carbon nano-additives for cold thermal energy storage. Appl Energy 2015; 138: 193-201.

[20]Asadi A, Asadi M, Rezaniakolaei A, Rosendahl LA, Afrand M, Wongwises S. Heat transfer efficiency of $\mathrm{Al}_{2} \mathrm{O}_{3}$-MWCNT/thermal oil hybrid nanofluid as a cooling fluid in thermal and energy management applications: An experimental and theoretical investigation. Int J Heat Mass Transf 2018 117: 474-486.

[21]Zhao N, Guo L, Qi C, Chen T, Cui X. Experimental study on thermo-hydraulic performance of nanofluids in CPU heat sink with rectangular grooves and cylindrical bugles based on exergy efficiency. Energy Convers Manage 2019; 181: 235-246.

[22]Zhao N, Qi C, Chen T, Tang J, Cui X. Experimental study on influences of cylindrical grooves on thermal efficiency, exergy efficiency and entropy generation of CPU cooled by nanofluids. Int J Heat Mass Transf 2019; 135 : 16-32.

[23]Qi C, Hu J, Liu M, Guo L, Rao Z. Experimental study on thermo-hydraulic performances of CPU cooled by nanofluids. Energy Convers Manage 2017; 153 : 557-565.

[24]Qi C, Zhao N, Cui X, Chen T, Hu J. Effects of half spherical bulges on heat transfer characteristics of CPU cooled by $\mathrm{TiO}_{2}$-water nanofluids. Int $\mathrm{J}$ Heat Mass Transf 2018; 123: 320-330. 
772

773

774

775

776

777

778

779

780

781

782

783

784

785

786

787

788

789

790

791

792

793

[25] Sarafraz MM, Nikkhah V, Nakhjavani M, Arya A. Thermal performance of a heat sink microchannel working with biologically produced silver-water nanofluid: experimental assessment. Exp Therm Fluid Sci 2018; 91: 509-519.

[26] Sajid MU, Ali HM, Sufyan A, Rashid D, Zahid SU, Rehman WU. Experimental investigation of $\mathrm{TiO}_{2}$-water nanofluid flow and heat transfer inside wavy mini-channel heat sinks. J Therm Anal Calorim 2019; https://doi.org/10.1007/s10973-019-08043-9

[27] Arya A, Sarafraz MM, Shahmiri S, Madani SAH, Nikkhah V, Nakhjavani SM. Thermal performance analysis of a flat heat pipe working with carbon nanotube-water nanofluid for cooling of a high heat flux heater. Heat Mass Transf 2018; 54(4): 985-997.

[28]Sadeghinezhad E, Mehrali M, Rosen MA, Akhiani AR, Latibari ST, Mehrali M, Metselaar HSC. Experimental investigation of the effect of graphene nanofluids on heat pipe thermal performance. Appl Therm Eng 2016; 100: 775-787.

[29]Shi L, He Y, Hu Y, Wang X. Thermophysical properties of $\mathrm{Fe}_{3} \mathrm{O}_{4} @ \mathrm{CNT}$ nanofluid and controllable heat transfer performance under magnetic field. Energy Convers Manage 2018; 177: 249-257.

[30] Selimefendigil F, Öztop HF. Corrugated conductive partition effects on MHD free convection of CNT-water nanofluid in a cavity. Int J Heat Mass Transf 2019; 129: 265-277.

[31] Selimefendigil F, Öztop HF. Mixed convection of nanofluids in a three dimensional cavity with two adiabatic inner rotating cylinders. Int J Heat Mass 
[32] Sajjadi H, Delouei AA, Izadi M, Mohebbi R. Investigation of MHD natural convection in a porous media by double MRT lattice Boltzmann method utilizing MWCNT-Fe ${ }_{3} \mathrm{O}_{4} /$ water hybrid nanofluid. Int $\mathrm{J}$ Heat Mass Transf 2019; 132: 1087-1104.

[33] Sheremet MA, Pop I, Mahian O. Natural convection in an inclined cavity with time-periodic temperature boundary conditions using nanofluids: application in solar collectors. Int J Heat Mass Transf 2018; 116: 751-761.

[34]Miroshnichenko IV, Sheremet MA, Oztop HF, Abu-Hamdeh N. Natural convection of alumina-water nanofluid in an open cavity having multiple porous layers. Int J Heat Mass Transf 2018; 125: 648-657.

[35]Miroshnichenko IV, Sheremet MA, Oztop HF, Abu-Hamdeh N. Natural convection of $\mathrm{Al}_{2} \mathrm{O}_{3} / \mathrm{H}_{2} \mathrm{O}$ nanofluid in an open inclined cavity with a heat-generating element. Int J Heat Mass Transf 2018; 126: 184-191.

[36]Bondarenko DS, Sheremet MA, Oztop HF, Ali ME. Natural convection of $\mathrm{Al}_{2} \mathrm{O}_{3} / \mathrm{H}_{2} \mathrm{O}$ nanofluid in a cavity with a heat-generating element. Heatline visualization. Int J Heat Mass Transf 2019; 130: 564-574.

[37] Sheremet MA, Pop I. Effect of local heater size and position on natural convection in a tilted nanofluid porous cavity using LTNE and Buongiorno's models. J Mol Liq 2018; 266: 19-28.

[38] Ma Y, Mohebbi R, Rashidi MM, Yang Z, Sheremet MA. Numerical study of MHD nanofluid natural convection in a baffled U-shaped enclosure. Int $\mathbf{J}$ Heat 
Mass Transf 2019; 130: 123-134.

817 [39] Sheikholeslami M, Shehzad SA, Li Z. Water based nanofluid free convection heat 818 transfer in a three dimensional porous cavity with hot sphere obstacle in existence of Lorenz forces. Int J Heat Mass Transf 2018; 125: 375-386.

820

821

[40] Sheikholeslami M, Seyednezhad M. Simulation of nanofluid flow and natural convection in a porous media under the influence of electric field using CVFEM. Int J Heat Mass Transf 2018; 120: 772-781.

[41] Sheikholeslami M, Rokni HB. Numerical modeling of nanofluid natural convection in a semi annulus in existence of Lorentz force. Comput Method Appl Mechanics Eng 2017; 317: 419-430.

[42] Xu H, Xing Z. The lattice Boltzmann modeling on the nanofluid natural convective transport in a cavity filled with a porous foam. Int Commun Heat Mass Transf 2017; 89: 73-82.

[43] Xu H, Gong L, Huang $\mathrm{S}, \mathrm{Xu} \mathrm{M}$. Flow and heat transfer characteristics of nanofluid flowing through metal foams. Int J Heat Mass Transf 2015; 83: $399-407$.

[44]Mohebbi R, Rashidi MM, Izadi M, Sidik NAC, Xian HW. Forced convection of nanofluids in an extended surfaces channel using lattice Boltzmann method. Int $\mathbf{J}$ Heat Mass Transf 2018; 117: 1291-1303.

[45] Karimi A, Afrand M. Numerical study on thermal performance of an air-cooled heat exchanger: Effects of hybrid nanofluid, pipe arrangement and cross section. Energy Convers Manage 2018; 164: 615-628. 
838

839

840

841

842

843

844

845

846

847

[46]Tirandaz N, Dehghan M, Valipour MS. Heat and fluid flow through a helical annulus enhanced by a porous material: A perturbation study. Appl Therm Eng 2017; 112: 1566-1574.

[47]Mehrali M, Sadeghinezhad E, Rosen MA, Latibari ST, Mehrali M, Metselaar HSC, Kazi SN. Effect of specific surface area on convective heat transfer of graphene nanoplatelet aqueous nanofluids. Exp Therm Fluid Sci 2015; 68: 100-108.

[48]Mehrali M, Sadeghinezhad E, Rosen MA, Akhiani AR, Latibari ST, Mehrali M, Metselaar HSC. Heat transfer and entropy generation for laminar forced convection flow of graphene nanoplatelets nanofluids in a horizontal tube. Int Commun Heat Mass Transf 2015; 66: 23-31.

[49]Mehrali M, Sadeghinezhad E, Rosen MA, Akhiani AR, Latibari ST, Mehrali M, Metselaar HSC. Experimental investigation of thermophysical properties, entropy generation and convective heat transfer for a nitrogen-doped graphene nanofluid in a laminar flow regime. Adv Powder Technol 2016; 27(2): 717-727.

[50] Vo DD, Alsarraf J, Moradikazerouni A, Afrand M, Salehipour H, Qi C. Numerical investigation of $\gamma$-AlOOH nano-fluid convection performance in a wavy channel considering various shapes of nanoadditives. Powder Technol 2019; 345: 649-657.

[51]Mirzaei M, Dehghan M. Investigation of flow and heat transfer of nanofluid in microchannel with variable property approach. Heat Mass Transf 2013; 49(12): 1803-1811. 
860

861

862

863

864

865

866

867

868

869

870

871

872

873

874

875

876

877

878

879

880

881

[52]Sun B, Yang A, Yang D. Experimental study on the heat transfer and flow characteristics of nanofluids in the built-in twisted belt external thread tubes. Int J Heat Mass Transf 2017; 107: 712-722.

[53]Sun B, Peng C, Zuo R, Yang D, Li H. Investigation on the flow and convective heat transfer characteristics of nanofluids in the plate heat exchanger. Exp Therm Fluid Sci 2016; 76: 75-86.

[54]Sun B, Lei W, Yang D. Flow and convective heat transfer characteristics of $\mathrm{Fe}_{2} \mathrm{O}_{3}$-water nanofluids inside copper tubes. Int Commun Heat Mass Transf 2015; 64: $21-28$

[55] Sheikholeslami M, Ganji DD. Heat transfer improvement in a double pipe heat exchanger by means of perforated turbulators. Energy Convers Manage 2016; 127: 112-123.

[56] Sheikholeslami M, Bhatti MM. Forced convection of nanofluid in presence of constant magnetic field considering shape effects of nanoparticles. Int $\mathrm{J}$ Heat Mass Transf 2017; 111: 1039-1049.

[57] Sheikholeslami M. Magnetohydrodynamic nanofluid forced convection in a porous lid driven cubic cavity using Lattice Boltzmann method. J Mol Liq 2017; 231: 555-565.

[58] Sheikholeslami M, Hayat T, Alsaedi A. Numerical simulation of nanofluid forced convection heat transfer improvement in existence of magnetic field using lattice Boltzmann method. Int J Heat Mass Transf 2017; 108: 1870-1883.

[59] Sheikholeslami M, Vajravelu K. Forced convection heat transfer in 
$\mathrm{Fe}_{3} \mathrm{O}_{4}$-ethylene glycol nanofluid under the influence of Coulomb force. $\mathrm{J}$ Mol Liq 2017; 233: 203-210.

[60] Sheikholeslami M, Hayat T, Alsaedi A, Abelman S. Numerical analysis of EHD nanofluid force convective heat transfer considering electric field dependent viscosity. Int J Heat Mass Transf 2017; 108: 2558-2565.

[61]Ranjbarzadeh R, Karimipour A, Afrand M, Isfahani AHM, Shirneshan A. Empirical analysis of heat transfer and friction factor of water/graphene oxide nanofluid flow in turbulent regime through an isothermal pipe. Appl Therm Eng 2017; 126: 538-547.

[62]Moradikazerouni A, Afrand M, Alsarraf J, Mahian O, Wongwises S, Tran MD. Comparison of the effect of five different entrance channel shapes of a micro-channel heat sink in forced convection with application to cooling a supercomputer circuit board. Appl Therm Eng 2019; 150: 1078-1089.

[63]Dehghan M, Valipour M S, Saedodin S. Microchannels enhanced by porous materials: heat transfer enhancement or pressure drop increment?. Energy Convers Manage 2016; 110: 22-32.

[64]Dehghan M, Daneshipour M, Valipour MS. Nanofluids and converging flow passages: A synergetic conjugate-heat-transfer enhancement of micro heat sinks. Int Commun Heat Mass Transf 2018; 97: 72-77.

[65]Nojoomizadeh M, Karimipour A, Firouzi M, Afrand M. Investigation of permeability and porosity effects on the slip velocity and convection heat transfer rate of $\mathrm{Fe}_{3} \mathrm{O}_{4} /$ water nanofluid flow in a microchannel while its lower half filled 
by a porous medium. Int J Heat Mass Transf 2018; 119: 891-906.

[66]Moradikazerouni A, Afrand M, Alsarraf J, Wongwises S, Asadi A, Nguyen TK. Investigation of a computer CPU heat sink under laminar forced convection using a structural stability method. Int J Heat Mass Transf 2019; 134: 1218-1226.

[67]Ranjbarzadeh R, Isfahani AM, Afrand M, Karimipour A, Hojaji M. An experimental study on heat transfer and pressure drop of water/graphene oxide nanofluid in a copper tube under air cross-flow: applicable as a heat exchanger. Appl Therm Eng 2017; 125: 69-79.

[68]Biglarian M, Gorji MR, Pourmehran O, Domairry G. $\mathrm{H}_{2} \mathrm{O}$ based different nanofluids with unsteady condition and an external magnetic field on permeable channel heat transfer. Int J Hydrogen Energ 2017; 42(34): 22005-22014.

[69]Naphon P, Wiriyasart S. Pulsating flow and magnetic field effects on the convective heat transfer of $\mathrm{TiO}_{2}$-water nanofluids in helically corrugated tube. Int J Heat Mass Transf 2018; 125: 1054-1060.

[70]Naphon P, Wiriyasart S. Experimental study on laminar pulsating flow and heat transfer of nanofluids in micro-fins tube with magnetic fields. Int J Heat Mass Transf 2018; 118: 297-303.

[71]Naphon P, Wiriyasart S, Arisariyawong T. Artificial neural network analysis the pulsating Nusselt number and friction factor of $\mathrm{TiO}_{2} /$ water nanofluids in the spirally coiled tube with magnetic field. Int J Heat Mass Transf 2018; 118 : 1152-1159.

[72]Naphon P, Nakharintr L, Wiriyasart S. Continuous nanofluids jet impingement 

126: 924-932.

928 [73]Zhai X, Qi C, Pan Y, Luo T, Liang L. Effects of screw pitches and rotation angles 929 on flow and heat transfer characteristics of nanofluids in spiral tubes. Int $\mathbf{J}$ Heat Mass Transf 2019; 130: 989-1003.

[74]Mei S, Qi C, Luo T, Zhai X, Yan Y. Effects of magnetic field on thermo-hydraulic 
950 [80]Qi C, Yang L, Chen T, Rao Z. Experimental study on thermo-hydraulic performances of $\mathrm{TiO}_{2}-\mathrm{H}_{2} \mathrm{O}$ nanofluids in a horizontal elliptical tube. Appl Therm Eng 2018; 129: 1315-1324.

[81]Ehyaei MA, Rosen MA. Optimization of a triple cycle based on a solid oxide fuel cell and gas and steam cycles with a multiobjective genetic algorithm and energy, exergy and economic analyses. Energy Convers Manage 2019; 180: 689-708.

[82]Hosseinpour J, Sadeghi M, Chitsaz A, Ranjbar F, Rosen MA. Exergy assessment and optimization of a cogeneration system based on a solid oxide fuel cell integrated with a Stirling engine. Energy Convers Manage 2017; 143: 448-458.

[83] Moharramian A, Soltani S, Rosen MA, Mahmoudi SMS, Bhattacharya T. Modified exergy and modified exergoeconomic analyses of a solar based biomass co-fired cycle with hydrogen production. Energy 2019; 167: 715-729.

[84]Rose JW. Heat-transfer coefficients, Wilson plot and accuracy of thermal measurements. Exp Therm Fluid Sci 2004; 28(2-3): 77-86.

[85]Gnielinski V. New equations for heat and mass-transfer in turbulent pipe and channel flow. Int Chem Eng 1976; 16(2): 359-368.

[86]Pak BC, Cho YI. Hydrodynamic and heat transfer study of dispersed fluids with submicron metallic oxide particles. Exp Heat Transfer Int J 1998; 11(2): 151-170.

[87]Kline SJ. Describing uncertainty in single sample experiments. Mech Eng 1953; 75: 3-8. 
970 [88]Qi C, Liang L, Rao Z. Study on the flow and heat transfer of liquid metal based 971 nanofluid with different nanoparticle radiuses using two-phase lattice Boltzmann 972 method. Int J Heat Mass Transf 2016; 94: 316-326.

973 [89] Ma L, Yang J, Liu W, Zhang X. Physical quantity synergy analysis and efficiency 974 evaluation criterion of heat transfer enhancement. Int $\mathrm{J}$ Therm Sci 2014; 80: 975 23-32. 